Article

\title{
Social Cohesion and Neighbor Interactions within Multifamily Apartment Buildings: Challenges of COVID-19 and Directions of Action
}

\author{
Branislava Stoiljković
}

Citation: Stoiljković, B. Social Cohesion and Neighbor Interactions within Multifamily Apartment Buildings: Challenges of COVID-19 and Directions of Action.

Sustainability 2022, 14, 738. https:// doi.org/10.3390/su14020738

Academic Editors: Serafeim Polyzos and Dimitrios Tsiotas

Received: 15 December 2021

Accepted: 8 January 2022

Published: 10 January 2022

Publisher's Note: MDPI stays neutral with regard to jurisdictional claims in published maps and institutional affiliations.

Copyright: (C) 2022 by the author. Licensee MDPI, Basel, Switzerland. This article is an open access article distributed under the terms and conditions of the Creative Commons Attribution (CC BY) license (https:// creativecommons.org/licenses/by/ $4.0 /)$.
Department of Housing, Faculty of Civil Engineering and Architecture, University of Niš, 18000 Niš, Serbia; branislava.stoiljkovic@gaf.ni.ac.rs

\begin{abstract}
Relations among neighbors are a key indicator of the strength of a local social community, contribute to social cohesion and are an important factor in achieving a higher level of social sustainability. On the other hand, the environment in which people live plays an important role in encouraging social contacts and developing relationships between people. In order to establish social interactions between neighbors within a multifamily apartment building (MFAB), it is necessary to provide adequate spaces for communication between residents. This was especially emphasized during the mobility restrictions caused by COVID-19, although this necessity is permanent. This paper analyzes the influence of the physical characteristics of common spaces in MFABs on the quality and intensity of contacts among residents of MFABs in the City of Niš, Serbia. In order to determine the current quality of these spaces as a physical framework for interactions among residents and to identify the wishes of users regarding interactions with neighbors in these spaces before and during COVID-19 pandemic restrictions, a survey was conducted. The analysis of the survey results and numerous examples of housing design led to (1) the formation of guidelines for future designs of MFABs and (2) recommendations for redefining the standards regulating the field of housing construction in the region, both applicable during the period of the pandemic and after it.
\end{abstract}

Keywords: multifamily apartment buildings; neighbors; social interactions; common spaces; COVID-19; social cohesion; social sustainability

\section{Introduction}

The grouping of residents in a multifamily apartment building (MFAB) is without any specific connections, and the spatial proximity will not itself guarantee their sociological closeness [1,2]. With the increase in the total number of residents, the possibility for the neighbors to know each other decreases and the feeling of belonging to a certain social group weakens. Thus, multifamily housing is often characterized by weaker social relationships [3,4] and a lack of socializing among the residents [5].

In contrast to less urban areas with dominant single-family housing, in which friendly ties between neighbors are frequent and widespread, for more densely populated areas with predominant multifamily housing, strong neighbor ties are not common [6-8]. On the contrary, there is a noticeable negative impact according to various social criteria, such as social cohesion, social interactions and community building $[3,4,9,10]$. Higher housing density, characteristic for areas with MFABs, impairs social interactions [11], reduces the degree of neighbor ties and trust [12,13] and can lead to alienation among people [5]. Nevertheless, the need for housing in MFABs in cities, which has existed throughout history, is particularly pronounced today and it is emerging as the economic, social and moral duty of modern society [14].

Having in mind that neighbor relations are a key indicator of the strength of local social communities $[15,16]$ and that they can contribute to social cohesion [2], which is considered a relevant element of social prosperity [13,17], as well as the fact that the physical 
environment plays an important role in encouraging social contacts $[2,18]$, it is obvious that there is a need to provide adequate spaces for communication between neighbors in MFABs. This was especially emphasized during the lockdowns and mobility restrictions caused by the COVID-19 pandemic, when people were obliged to stay home to prevent the spread of the infection. Since housing had crucial importance during lockdown periods [19], MFABs have become more than merely a living space [20]. The pandemic has brought many changes to people's lives. Among other things, the enforced confinement has encouraged residents of MFABs to enrich and improve ties with their neighbors [21]. Accordingly, the pandemic began to make changes in the requirements for housing design [20,22,23].

Although numerous studies have addressed the importance of neighbor relations for the mental health of the local community and society as a whole, as well as the interrelationship between the housing environment and residents' social interactions, insufficient attention has been paid to the relationship between the design characteristics of the spaces outside the apartments within an MFAB, the so-called common spaces, and the quality of social communication among neighbors. Specifically, this type of research has neither been done for the territory of Serbia, nor for the region for the period after the outbreak of the COVID-19 pandemic. This paper deals with the analysis of the influence of the physical characteristics of the circulation spaces of the MFAB and the premises inside the MFAB intended for socializing on the social activities of the residents, and does not address common spaces such as shops, sports facilities, beauty salons or services within a building. In terms of temporal effects, the research was conducted after the outbreak of the COVID-19 pandemic; it includes topic analysis in the living conditions before and during the pandemic and gives conclusions that are applicable both in the period of the pandemic and after it.

The goals of this paper are:

1. recognizing the characteristics of common spaces within MFABs that have an influence in increasing social interactions;

2. surveying users on the importance of common spaces in MFABs for the quality of neighbor relations and identification of their preferences regarding these spaces;

3. defining guidelines for the design of common spaces in MFABs and recommendations for improving existing norms.

To achieve these goals, combined methods were used-the method of empirical cognition, method of observation, conversations with residents and a survey.

The paper concludes that carefully and well-designed common areas of an MFAB can be a factor that promotes and encourages the development of social ties among residents and that they can contribute to strengthening social cohesion in the neighborhood, noting that the implementation of the recommendations should not be temporary, but a permanent measure.

The remainder of this paper is organized as follows. The next section reviews previous research on neighbor interactions and the physical environment that favors such relationships. Section 3 explains the potential of common spaces in MFABs to initiate social ties among neighbors. Section 4 describes the context and main characteristics of housing in MFABs in Serbia, and looks at the data and methods applied. Then, the results are presented in Section 5. Section 6 provides an analysis of the results and discusses the research findings. Finally, Section 7 draws conclusions and indicates some considerations for further research.

\section{Literature Review}

\subsection{Importance of Relationships between Neighbors}

Neighborhood relations represent a significant part of every person's social network $[8,24]$. Good relations between neighbors contribute to the general satisfaction with housing [25]. They not only provide well-being at the individual level, but also at the level of the community and the whole society [8,26], and are an important factor in achieving a greater extent of social sustainability. Since they generate positive outcomes, it is not 
surprising that strengthening social relations in the neighborhood is one of the priorities of sustainable housing policies $[8,25,27]$.

In conditions of mobility restrictions due to COVID-19 measures, when people were forced not to leave their homes, the need to communicate with others, at least to a minimal extent, could be met only within the buildings in which they lived. Although physical distancing was emphasized to reduce the spread of the disease, it did not mean emotional distancing [28] and increased social isolation [29], and relations between neighbors were almost the only contacts with people outside their households. Some research even shows that social interaction and support were increased during this crisis and that people seemed to help and care for each other even more [21].

Relationships between neighbors in most cases do not represent strong ties [30], which means that people do not have close friends among neighbors, generally do not visit each other and do not consider their neighbors to be part of their core network $[13,16,31]$. Connections between neighbors usually include unintentional everyday contacts, daily mutual recognition within common spaces, nodding acquaintance, greetings in passing, short message exchanges and superficial links of sociability $[4,8,13,32]$. Although people usually have lots of these connections, they do not mainly share the same social circles, meaning that these links can act as bridges into new groups; therefore, these connections, in non-pandemic conditions, could be a link with a wider range of social circles [30]. Everyday neighbor ties play an important role in the richness and liveliness of social life [4,33], can improve residents' prosperity and happiness [4,10], can contribute to more familiarity and feelings of safety $[26,34]$ and are associated with an improved mental health status $[3,35]$. Social interactions between neighbors are an important factor of neighborhood cohesion $[13,25,27,34]$ and neighborhood attachment $[4,26,34]$. Therefore, they are a major precondition for the success of a sustainable society [36] and an important goal for policy makers [7,34]. The new reality imposed by COVID-19 puts the focus more than ever on the importance of neighborly relations [37], especially within MFABs themselves.

\subsection{Importance of Physical Environment for Relationships between Neighbors}

Numerous authors agree that the way in which the physical environment is designed may lead to better relationships among the residents. In this sense, the semi-public zone of an MFAB, which is available to all residents, can significantly contribute to the improvement of communications between neighbors. Speaking on activities in public spaces between buildings, Gehl concludes that when the quality of public spaces is high, optional activitiesactivities in which one participates if there is a desire to do so and if time and place allow it-occur more frequently, and therefore the number of social activities is also increasing; he thus implies that social activities are indirectly supported whenever they are given better conditions in public spaces [38]. Hoogland identifies several aspects of the housing environment that are thought to affect the intensity of social ties in a neighborhood, such as the number of housing units in a building, number of floors, number of units per floor, number of units sharing one entrance, configuration of units in relation to each other, etc.; by analyzing a concept of grading the transition from public to private space, she concludes that stronger social ties are expected among residents of a building with more privacy gradients [36]. Bee and Im also note the importance of the size of the social group and warn that too many users sharing a common hall or circulation space will make such spaces anonymous, make it difficult for neighbors to recognize each other and discourage social connections; therefore, they recommend providing more social spaces suitable for social interactions and creating micro-communities comprising smaller groups of residents (for example, by floors) [10]. Muhuri and Basu identify the ground floor lobby, floor lobby and hallways as interactional indoor spaces, providing moderate to high opportunities for social interrelation; they perceive that certain attributes of these spaces (such as the presence of seating areas or the view of outdoor activity spaces and the scenic landscape) will contribute to the achievement of stronger ties and a sense of belonging [5]. By investigating the influence of neighborhood characteristics on social interaction among 
occupants of MFABs, Nguyen et al. conclude that circulation areas-hallways, lifts, lobbies, entrance halls, etc.- -are the most popular spaces for social interactions; in addition to their primary purpose, residents use these areas for various purposes of social interaction: children play football or ride a bike, mothers feed their children, grandmothers monitor children who play, men gather, drink and smoke in the hallways [4]. Gallery access to the apartments, which resembles a pedestrian street from which one directly enters the housing units, may facilitate the rapprochement of residents and enhance their mutual communication, but this may not always be the case; as Ebner and Klaffke note, other factors play a significant role in this, such as the width of the gallery, its orientation, its position in relation to the environment, the number of floors and the number of apartments per floor [39]. Recognizing the importance of shared open spaces for developing social connections among occupants in high-rise buildings, Ghazali et al. promote the "sky neighborhood" concept; they propose a new kind of arrangement with accesses to each apartment via six-story-high landscaped courtyards, in this way eliminating corridors and improving the social and environmental quality of intermediate spaces in high-rise housing buildings [40]. On the other hand, in cases where potential meeting spaces are lacking in the housing environment, opportunities for casual encounters among residents are weak; thus, Bektaş and Taşan-Kok notice that individual entrances to housing units are the subject of most occupants' complaints about neighborly relations, as they could at least meet someone unexpectedly in the common hall [2]. Speaking about specific solutions for the built environment from the perspective of social interactions during the COVID-19 pandemic, Pinheiro and Luís give several suggestions for common spaces in buildings: widening of circulation spaces and entrance halls, existence of external spaces (balcony, terrace, flat roof) accessible to all residents, natural lighting and ventilation, favoring minimalist design and the use of easily washable equipment and materials [23].

\subsection{Improving the Existing Built Environment after the COVID-19 Pandemic}

The COVID-19 pandemic is a global health crisis that has affected all spheres of life. Many countries are already developing recovery strategies for life after COVID-19, involving measures and plans in various segments of life. As housing in cities is particularly affected by this pandemic, numerous studies are already making recommendations for the improvement of urban housing in a post-COVID-19 world. Cities such as Vienna, Liverpool and Rotterdam have launched measures to increase the supply of adequate housing and improve the existing one, in order to prevent the risks of transmitting the disease [41].

Although it could be expected that a reduction in housing density in cities is recommended (due to the need for physical distancing measures), the findings of some studies actually suggest that increased housing density alone is not directly related to higher infection rates and that denser areas, as compared to more sprawling ones, tend to have lower death rates [42]. Capolongo et al. argue that it is necessary to ensure that the built environment can prevent the spread of infectious diseases and that urban health goals are integrated into the housing strategy; they particularly emphasize the importance of housing flexibility and designing semi-private and collective spaces [43]. Honey-Rosés et al. examine the emerging questions on the impact of COVID-19 on public space, in terms of position, design, dimensions, equipment and even the purpose itself, leaving the possibility for this crisis to permanently and substantially change people's attitudes towards public spaces [44]. Some authors suggest that housing design strategies should focus on larger and more livable living spaces $[23,45]$ and that urban and architectural design measures that promote distancing also have secondary benefits (besides the ability to maintain a physical distance) [46].

\section{Common Spaces in an MFAB - Characteristics and Social Potential}

Occupants of MFABs generally do not know each other before moving into the building. Often, a lot of time after moving in, they discover how different they really are. Since social connections are encouraged when residents have the opportunity to meet and when 
they have an adequate space to meet [47], i.e., since the characteristics of common spaces within MFABs are important for the quality of neighbor relations, one of the challenges facing designers is how to design common spaces within which the occupants can become closer and form a community, while, at the same time, living as individuals. During the COVID-19 crisis, the challenge is even greater because it is necessary to simultaneously provide physical distance in common spaces and create a suitable architectural framework for intensifying neighbor relations and strengthening the community. The analysis of housing architectural schemes shows the possibilities that some types of structures can or cannot offer in this respect. However, these are still only assumptions and possibilities, not certainty. Common spaces of MFABs offer opportunities for social interaction, but residents need to take advantage of this opportunity; this means that there needs to be an affinity for realizing social interactions among occupants. The social component of common spaces also depends on many factors that are outside the framework of architecture [48].

Common spaces in MFABs include circulation spaces (staircases, hallways, entrance halls, etc.), common social rooms (children's playroom, residents' club, hobby rooms, etc.) and service rooms (laundries and dryers, waste disposal facilities, supply system facilities, etc.) [49]. This research covers the circulation spaces of the building and common premises intended for socializing.

The use of common spaces in the building leads to more or less encounters between the occupants of the building and can lead to good neighbor relations; spontaneous and unplanned social contacts occur in spaces for circulation, while common social rooms are designated for intentional gathering and socializing. However, as has already been emphasized, the users of the MFAB form a heterogeneous group and their physical closeness, as well as the existence of spaces for common use, do not guarantee the realization of stronger social ties.

As, in the conditions of lockdown periods, the users of an MFAB cannot be forbidden to move within the building, the common spaces come to life and are reconsidered as spaces suitable for establishing social interactions.

\subsection{Circulation Spaces}

Circulation spaces in MFABs, although primarily intended for passage from the entrance to the building to the entrance to the apartment, can be suitable places for social interactions between occupants. While most circulation spaces in MFABs do not encourage meetings and socializing among residents, with a careful and thoughtful design, they can become social hubs [10] and places for pleasant encounters.

Even in utopian social housing projects, such as Godin's Familisteria from the 19th century, there was an idea to design access and circulation spaces in buildings as an architectural framework for interaction between users [50]. The Spangen Quarter in Rotterdam, from the beginning of the 20th century, is a very significant example of such an approach to design. The apartments on the second and third floors are accessed through an open gallery whose width varies and which is designed as a raised pedestrian street where residents meet and talk, children play, the elderly rest, merchandisers offer goods, etc. [51] (Figure 1a,b). This scheme is based on an accepted cultural model and redefines the idea of a traditional residential street of small Dutch towns [52].

However, the attribution of social value to spaces for access and circulation, as well as the "socialization" of common spaces, raises many problems and issues. It has long been accepted that ceremonial, grandiose staircases and halls in MFABs are an unnecessary luxury, because it does not make sense to enhance a space that is not intended for people to stay in in an aesthetic sense [50]. It was the reduction of costs for staircases, hallways and other circulation spaces that stigmatized numerous residential developments of the 20th century. 


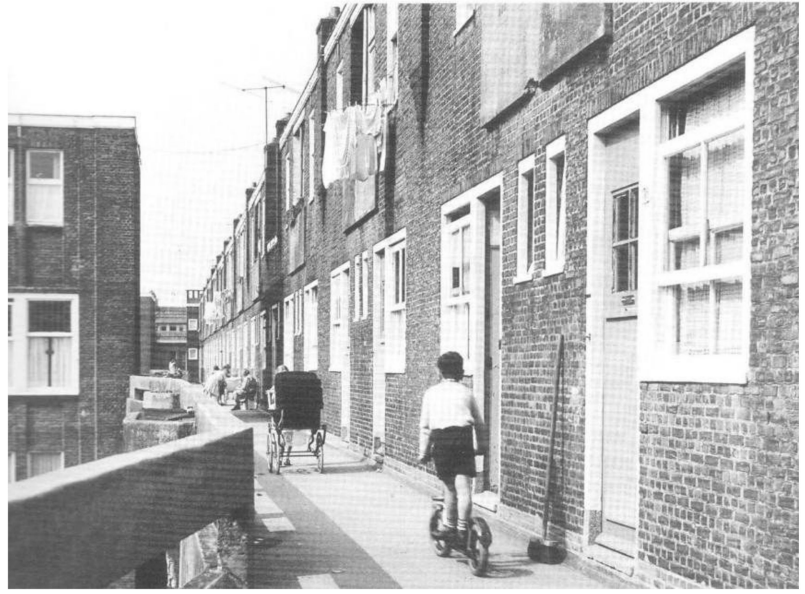

(a)

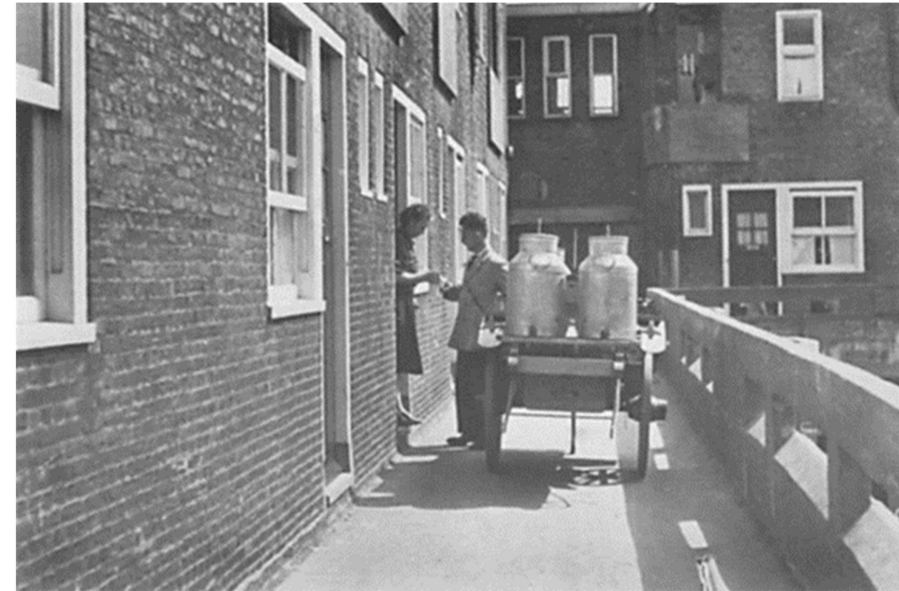

(b)

Figure 1. Spangen Quarter, Rotterdam - an open gallery access conceived as a pedestrian street for various activities: (a) Source: https: / / www.deoudrotterdammer.nl/archief/dor/2012/week38_ jaargang8 / files/assets/basic-html/page15.html (accessed on 25 September 2021); (b) Source: http: / / besems.eu/2017/12/10/justus-van-effen-kwartier-rotterdam/ (accessed on 25 September 2021).

Due to cost reductions, access areas to apartments in MFABs are now being designed to be as short as possible. These spaces are reduced to a functional minimum, so the occupants usually pass through them quickly, without unnecessary delay [53]. However, by reducing the access and circulation spaces in MFABs to the minimum dimensions defined by the norms, the potential of these spaces in a social sense is lost. On the other hand, if they are carefully and comprehensively designed and not reduced to the minimum dimensions, they can serve as a suitable physical framework for social interactions among users (Figure 2a,b).

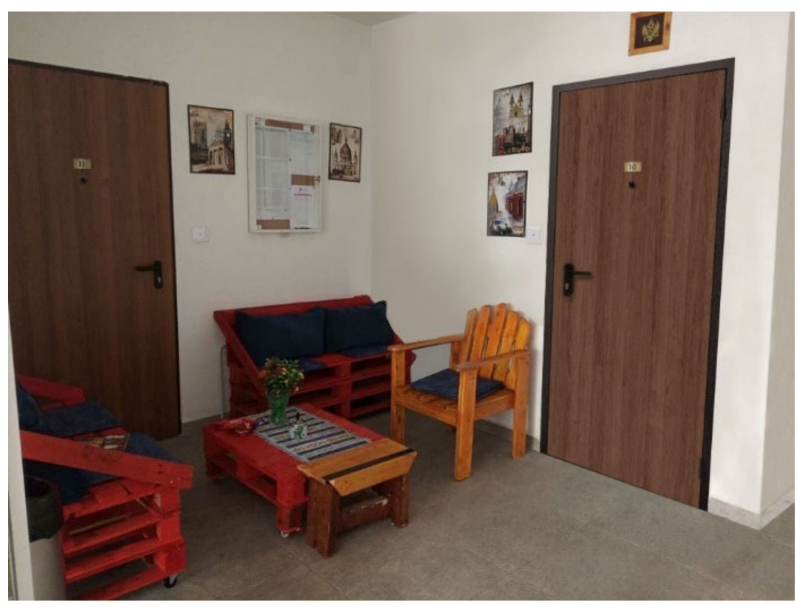

(a)

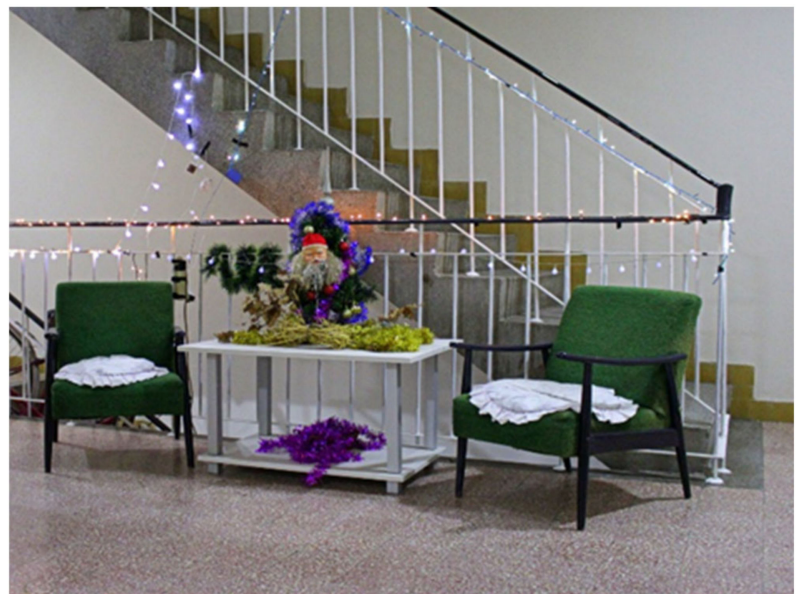

(b)

Figure 2. Circulation spaces as a suitable physical framework for socializing: (a) semi-private space in front of a small group of apartments. Source: Stoiljković; (b) seating area within a landing. Source: https: / / distrikt.rs/slozni-stanari-uredili-zgradu-za-primer/ (accessed on 3 October 2021); photo credit: J. Gubelić.

In residential schemes in which circulation space is reduced only to the staircase and landing that connects the staircase with the apartments, entrances to the apartments are placed close to each other and the common space in front of them is cramped, which can cause certain tensions and discomfort. A possible solution for creating an area suitable for communication between neighbors is to form a semi-private space in front of a small group of apartments on the floor (one (Figure 3) or more (Figure 4) such spaces per floor, 
depending on the number of apartments), which would allow housing units to belong to a particular subcommunity.

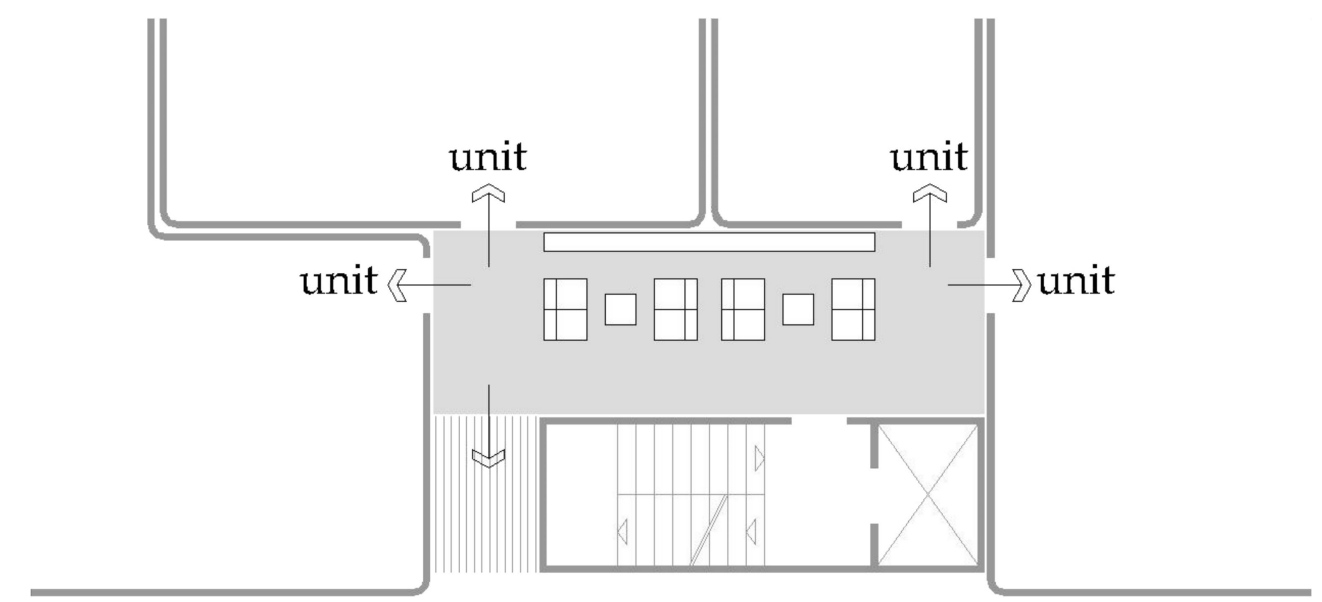

Figure 3. Semi-private space in front of a small group of apartments. Source: Stoiljković.

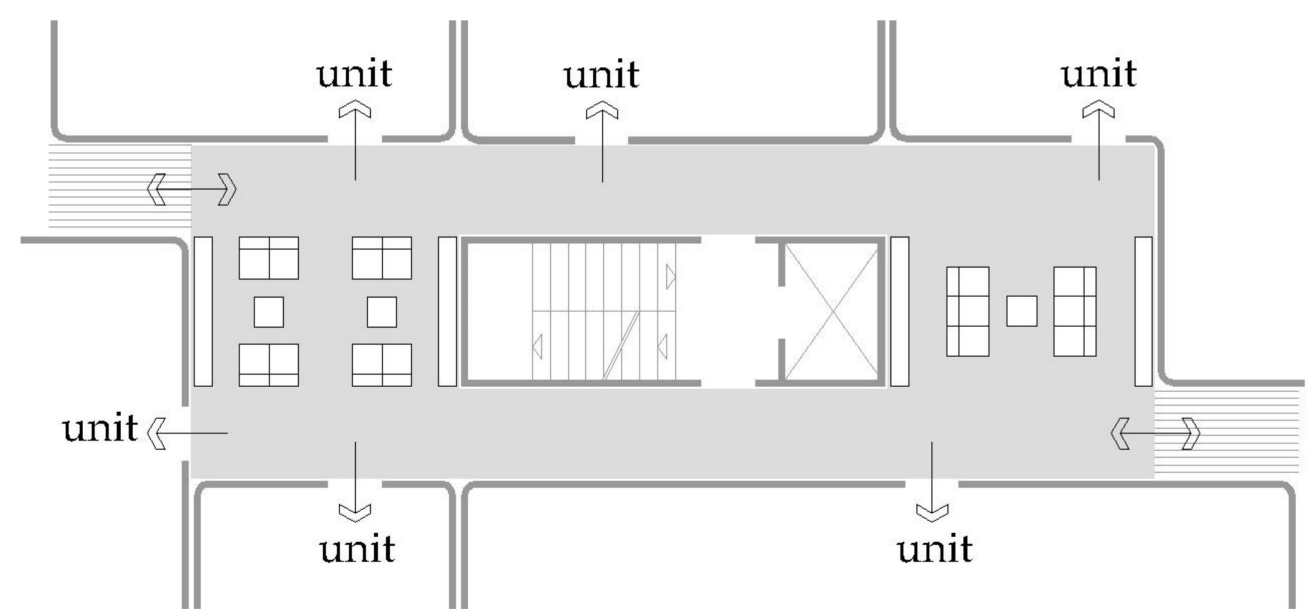

Figure 4. More semi-private spaces per floor, each one in front of a small group of apartments. Source: Stoiljković.

Since a corridor, as a type of access to multiple apartments per floor, usually has no natural lighting, there are generally no additional activities in it and its purpose is reduced to the basic one-circulation. By omitting certain housing units or their parts along the corridor, spaces with natural light, suitable for gathering, socializing and talking among the residents, emerge (Figure 5). They can be closed or open and can also run through multiple floors. Moreover, by inserting lightwells along the corridor throughout the entire height of the building, it is possible for natural light to penetrate the corridor, thus increasing the social component of the circulation space.

Frequently, the image of the street is used as a metaphor for gallery access in MFABs; its social function, as a common space that encourages contacts, is cited as the main advantage of this type of horizontal circulation. The gallery access is attractive as a walking path, as an outdoor space next to an apartment used for growing flowers, as a place to sit, rest or communicate with neighbors and, due to the proximity of housing units, as a suitable place for children to play. By planning several widened areas along the gallery access, places suitable for residents to gather and converse are obtained (Figure 6). 


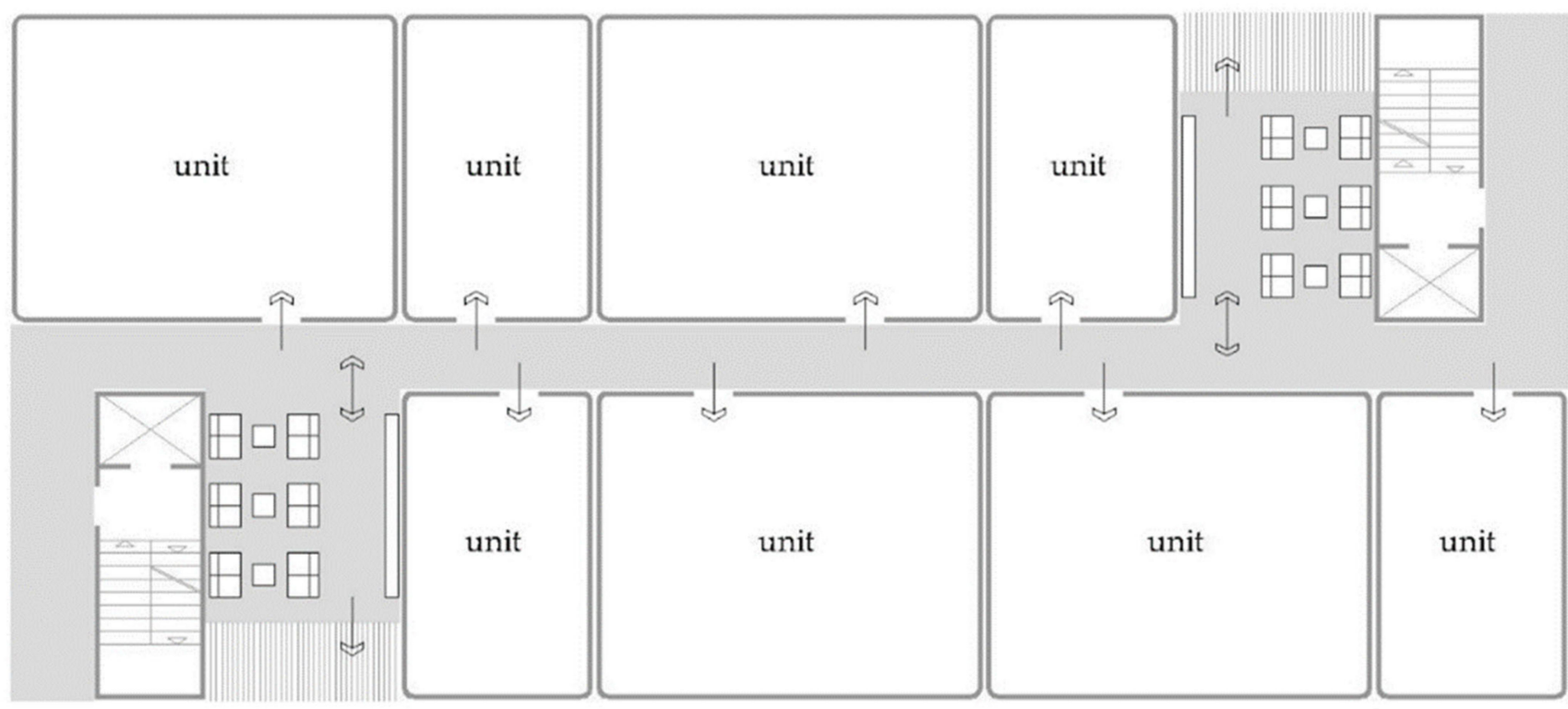

Figure 5. Spaces with natural light, suitable for socializing, made by omitting certain housing units or their parts along the corridor. Source: Stoiljković.

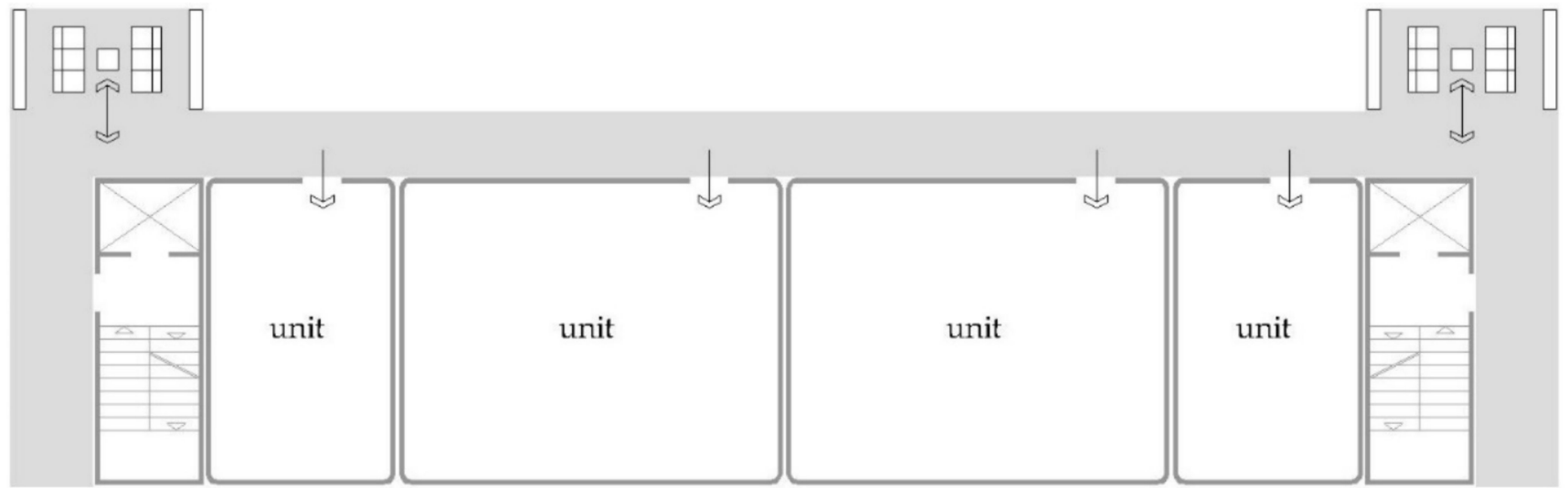

Figure 6. Widened areas along the gallery access, suitable for residents to gather and converse. Source: Stoiljković.

The very entrance to the building indicates the transition from the outer, open space to the closed, inner one and the gradation of the publicity of the space. In an MFAB, the entrance serves all (or almost all) residents of the building and should be recognizable, so that it can easily be spotted and identified by occupants as "their home". The entrance hall should be appropriately dimensioned with possible additional facilities according to the needs of the residents (Figure 7); the use of high-quality materials, fine interior finishes and installed equipment will make this space pleasant and suitable for establishing social interactions.

\subsection{Common Rooms and Areas Intended for the Socialization of Residents}

Planning and designing common rooms in MFABs intended for intensifying the social life of the occupants was an obligation during the socialist housing construction in the former Yugoslavia. They were used for children and youth gatherings, social activities of adults, as well as for children and adults' care [49], and their role was to improve housing conditions and reduce the alienation of people in large buildings. As such common areas were not privately owned, but were available to all occupants of the building, frequently, they were not adequately used and maintained, which inevitably resulted in the so-called "tragedy of the commons". Current domestic legislation in the 
field of housing construction does not recognize the need for designing these types of premises in MFABs [54]. However, spaces intended for the social activities of residents are still used in some buildings (Figure 8).

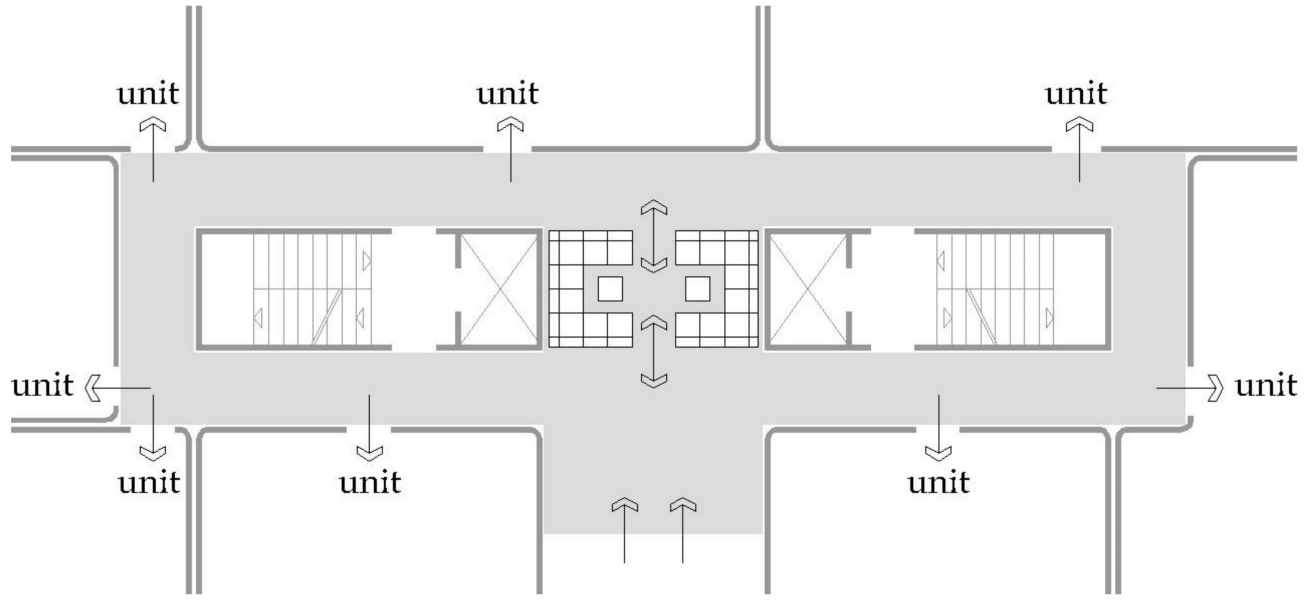

Figure 7. Entrance hall with a seating area. Source: Stoiljković.

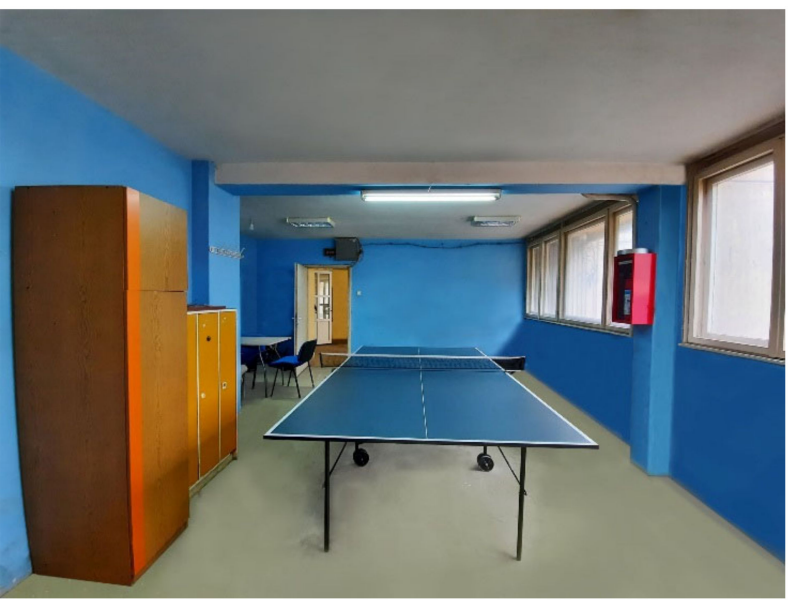

Figure 8. Common room originally designed for joint activities of residents. Source: Stoiljković.

A suitable position for these rooms can be next to the entrance hall (Figure 9), next to the circulation spaces, on the roof terraces, etc. By applying an adaptive reuse concept on the underused spaces within MFABs, common premises could be created whilst adding new social value [55], not only in the context of a pandemic.

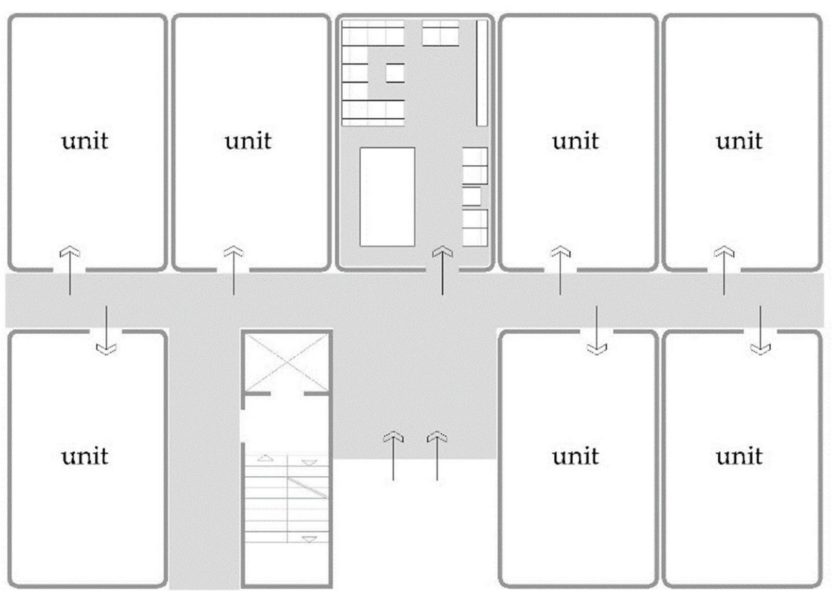

Figure 9. Possible position of the common room, next to the entrance hall. Source: Stoiljković. 
According to Ebner et al., a common roof terrace is one of the essential motifs of modernism and even positive effects on society were attributed to it [36]. Even though modern examples show that roof terraces have lost their ideological meaning, it is indisputable that they are suitable for a variety of activities-from sunbathing to recreation and gardening - and offer great potential for the improvement of social interaction (Figure 10). Roof terraces have proven to be an important resource of sociability, especially during lockdown [55]. After all, staying in the fresh air and sun are some of the measures to protect against the COVID-19 infection. Around the world, green roofs are increasingly being used. As green areas have a positive effect on the number of individuals involved in social activities [56,57], encourage people to be in the company of others [38] and promote community integration $[57,58]$, green roofs have great social value, in addition to environmental benefits. Community gardens, which can also be grown on the rooftops of MFABs, promote the socialization of residents, neighbor cohesion [59] and a sense of social connectedness [60], and they strengthen social sustainability [61].

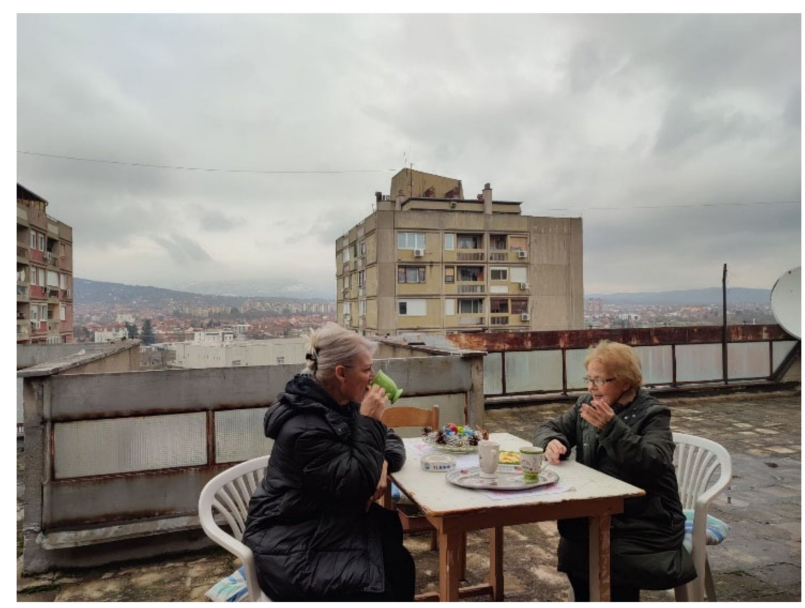

Figure 10. Roof terrace as an architectural framework for the improvement of social interaction. Source: Stoiljković.

\section{Materials and Methods}

\subsection{Context}

This research focuses on MFABs in Niš, Serbia. With over 260,000 inhabitants, the City of Niš is the third largest city in Serbia and covers an area of approximately 600 square kilometers. It is located in the south of Serbia and represents an important land and air traffic intersection of the Balkans and Southeast Europe. It is an important economic, university, cultural, religious and political center of Serbia. According to the 2011 Census, roughly half of the number of housing units (49.13\%) are located in MFABs in the entire territory of the City of Niš, while this percentage is significantly higher in urban areas $(65.30 \%)$ [62].

Niš has a temperate continental climate, with an average annual temperature of $11.9{ }^{\circ} \mathrm{C}$ and the most prevalent winds from the northwest and northeast [63]. This area is characterized by very warm summers and moderately dry winters. Considering climate change, climate conditions in Serbia generally have changed, which is manifested through a significant increase in temperature and a change in precipitation patterns. According to some research, Niš stands out as the urban area with the greatest thermal discomfort in Serbia, especially during the summer, with extremely hot and dry weather [64]. What is especially worrying is the increasing air pollution, especially during the winter months. Measurements of air quality in Niš reveal high concentrations of pollutants that often exceed recommended limit multiple times, and citizens are often advised to avoid outdoor activities.

Multifamily housing in Niš began to develop at the end of the 19th century; since then, it has gone through numerous social, cultural, organizational, functional and aesthetic 
phases of development. The entire multifamily housing stock in Niš is a mixture of different influences, periods and housing policies.

In the period between the two world wars, the renewal of the country and the development of industry led to a large influx of population into the cities, which caused a great demand for housing. Multifamily housing construction with rental apartments for different social and economic categories of the population began to develop. These apartments were built by private owners, housing cooperatives, construction companies, as well as wealthy industrialists [65]. During the period of socialism in Serbia, the construction of MFABs was completely controlled by the state. Multifamily housing was rational and economical, and seen as the ideologically desirable form of housing. The functional organization of apartments, as well as standards that regulated housing construction, were constantly improved.

In the late 1980s, European socialist countries switched to a transition program based on the imperatives of neo-liberalism (liberalization, privatization and minimization of the role of state in housing legislation), by applying the so-called shock therapy model, which was followed by a decrease in almost all social, economic and environmental indicators [66]. The privatization of land and state-owned dwellings is considered the most radical aspect of the transition [67]. Some authors underline the creation of a new urban identity, a real-estate bubble, deindustrialization, suburban industrialization and the rise of sociospatial inequalities as the main characteristics of post-socialist urban transformations [68]. After 1990, the state of Serbia rejected the system of financing public subsidized housing construction; the housing sector was abruptly and completely left to market forces and housing construction became a very profitable activity for investors. There was an evident constant conflict between regulations and reality, economic interests and social needs [66]. At the same time, the process of illegal construction has intensified. Some research shows that housing did not bring justice to marginalized groups affected by capitalist expropriation [69]. Legal regulations have been applied selectively. Due to a change in the political, social and economic circumstances, there was a change in the principles of planning and designing MFABs. Construction for the market led to a general rationalization that has resulted in a reduction in the quality of housing [14]. As a consequence of the lack of efficient residential and urban policy, extremely inefficient urban land use emerged [66].

Although similar circumstances could be seen in the surrounding countries after the 1990s and the housing privatization process [70-72], research shows that in some countries of the region, post-socialist housing has many advantages over housing from the socialist period and is of higher quality $[73,74]$. With regard to the sense of neighborhood, some authors claim that neighboring networks, neighborhood attachment and commitment could be described as quite high in the countries of the region [75-77].

One can justifiably assume that the conditions in MFABs in Niš, which are the subject of this paper, are not unique and that similar ones can be found in cities of similar size in the region, and that research conducted in Niš can provide information at a wider level. Due to the abovementioned factors, the City of Niš can be considered a relevant geographical framework for this type of research.

The selection of MFABs in which the survey was conducted was done so that all periods of construction were represented, as well as various forms of circulation spaces in MFABs.

\subsection{Database and Applied Methodology}

In order to analyze the residents' perspectives on the importance of the common spaces of the MFAB for the quality and intensity of neighborly communication, the author conducted a survey. The survey was conducted on a random sample of MFABs in Niš, Serbia, in the periods of September-October 2020 and March-May 2021. The total number of respondents was 387 . The sampling method did not result in discriminatory practice. Participation in the survey was entirely voluntary, with informed consent obtained and clearly documented from participants in advance. No sensitive personal data of respon- 
dents were collected during the survey. According to the Code of Professional Ethics of the University of Niš, ethical consent was not required for the planned research. The author visited the residents in their homes and asked them if they wanted to participate in the survey. All participants were fully informed that their anonymity was assured, why the research was being conducted and how their data would be used. Visits took place at different times of the day, so residents of all ages and different occupations participated in the survey.

The main objectives of the survey were: (1) identification of the current situation in MFABs from the perspective of the quality of common spaces and their potential for the development of social interactions and (2) research of needs and wishes of users in the context of developing neighborly relations, bearing in mind the conditions of mobility restrictions during the COVID-19 pandemic, but also life before the outbreak of the pandemic.

The following variables-objective building and household characteristics-were taken into account during the research: (a) access to the apartment, (b) period of construction, (c) number of floors in the building, (d) number of apartments per floor, (e) household structure, (f) form of ownership of the apartment, ( $g$ ) length of residence and (h) household income (Table 1). Access to the apartment directly explains the form of circulation spaces in the building. The period of construction of the building largely determines the quality of the organization of the architectural scheme, the existence of common spaces for socialization, the quality and current condition of the used materials, etc. The number of floors in the building and the number of apartments per floor define the size of the building and the size of the social group, which is especially important when it comes to neighborly interactions. Depending on the household structure, the priorities will be different-families with small children will have more needs for a monitored space for children to stay and play $[40,78,79]$, while households composed of the elderly will especially favor common areas where they can socialize with neighbors, as they are relatively more dependent on local ties than others [34]. Regarding the form of ownership of the apartment, many authors agree that occupants that rent their apartment have fewer relations with their neighbors, while owning an apartment has a positive impact on the creation and intensity of relationships with neighbors $[8,16,78]$. The length of residence also affects the intensity of relations in the neighborhood; a longer time of residence generally results in more frequent communication with neighbors and vice versa $[8,78]$. Numerous studies indicate that income levels have an impact on connections with other residents, so that users with higher incomes have better relationships with their neighbors and social support [13,31,78], while those with lower incomes are characterized by a lack of social ties with their neighbors and smaller community social networks $[13,80]$.

Table 1. Variables used in the survey and their representation as a of the total number of respondents.

\begin{tabular}{lc}
\hline \multicolumn{1}{c}{ Variable } & Percentage of Respondents \\
\hline (a) Access to the apartment & 77.78 \\
Centralized access & 6.72 \\
Gallery access & 13.95 \\
Corridor access & 1.55 \\
Individual entrances & \\
(b) Period of construction & 17.05 \\
Before 1945 & 50.13 \\
1945-1990 & 32.82 \\
After 1990 & \\
(c) Number of floors & 14.73 \\
Up to 3 floors & 49.35 \\
4-6 floors & 35.92 \\
More than 6 floors & \\
\hline
\end{tabular}


Table 1. Cont.

\begin{tabular}{lc}
\hline \multicolumn{1}{c}{ Variable } & Percentage of Respondents \\
\hline (d) Number of apartments per floor & 6.20 \\
1 & 50.65 \\
$2-4$ & 43.15 \\
5 or more & \\
(e) Household structure & 36.70 \\
Adults (no seniors, no children) & 10.59 \\
Senior citizens & 31.78 \\
Households with small children ( $\leq 15$ y.) & 20.93 \\
Mixed households (with children and seniors) & \\
(f) Form of ownership of the apartment & 74.93 \\
Owned & 25.07 \\
Rented & \\
(g) Length of residence (in years) & 15.24 \\
$<1$ & 24.30 \\
$1-5$ & 60.46 \\
$>5$ & \\
(h) Household income & 51.68 \\
Low-income household & 42.12 \\
Middle-income household & 6.46 \\
High-income household &
\end{tabular}

Determining the relation between the results of the survey according to these variables will contribute to a better and clearer understanding of them.

The questionnaire (Table 2) contained 13 questions grouped into 2 categories: (1) circulation spaces and (2) common rooms and areas intended for the socialization of residents. The questionnaire was designed so that the author entered the answers of the respondents by circling one or more offered answers. In the case of multiple-choice questions, respondents could even give a different answer if one was not offered in a particular form. The questions and offered answers were formulated clearly and unambiguously, so that the respondents could understand them regardless of their level of education. The survey relied on the personal impression and assessment of the respondents about the characteristics of the common spaces in the buildings and their importance for the quality of social interactions among neighbors. Results of a survey conducted within a broader research project (2015) on the topic of housing satisfaction in MFABs in Niš, Serbia, were used for comparison [81].

Table 2. Questionnaire.

\begin{tabular}{|c|c|c|}
\hline \multicolumn{3}{|c|}{ Circulation Spaces } \\
\hline 1. & $\begin{array}{c}\text { How do you assess the general quality } \\
\text { of circulation spaces (hallways, } \\
\text { staircases, entrance hall) in } \\
\text { the building? }\end{array}$ & $\begin{array}{l}\text { a. bad; } \\
\text { b. neither good nor bad; } \\
\text { c. good. }\end{array}$ \\
\hline 2. & $\begin{array}{l}\text { What do you consider to be the main } \\
\text { deficiency of hallways and staircases in } \\
\text { the building? (multiple and } \\
\text { non-predefined answers acceptable) }\end{array}$ & $\begin{array}{l}\text { a. insufficient dimensions; b. lack of } \\
\text { perceivability; c. poor natural lighting; } \\
\text { d. lack of outdoor views; e. lack of } \\
\text { additional equipment; f. poor } \\
\text { maintenance; g. lack of security; h. lack } \\
\text { of intimacy. }\end{array}$ \\
\hline 3. & $\begin{array}{l}\text { What do you consider to be the main } \\
\text { deficiency of the entrance hall in the } \\
\text { building? (multiple and } \\
\text { non-predefined answers acceptable) }\end{array}$ & $\begin{array}{l}\text { a. insufficient dimensions; b. lack of } \\
\text { perceivability; c. poor natural lighting; } \\
\text { d. lack of outdoor views; e. lack of } \\
\text { additional equipment; f. poor } \\
\text { maintenance; g. lack of security. }\end{array}$ \\
\hline
\end{tabular}


Table 2. Cont.

\begin{tabular}{|c|c|c|}
\hline \multicolumn{3}{|c|}{ Circulation Spaces } \\
\hline 4. & $\begin{array}{l}\text { Which of the following activities do } \\
\text { you use the hallways for? (multiple and } \\
\text { non-predefined answers acceptable) }\end{array}$ & $\begin{array}{l}\text { a. greeting in passing; b. chatting with } \\
\text { neighbors; c. longer conversations with } \\
\text { neighbors; d. children playing; } \\
\text { e. activities that do not involve } \\
\text { interactions with neighbors. }\end{array}$ \\
\hline 5. & $\begin{array}{l}\text { Which of the following activities would } \\
\text { you like to use hallways for? (multiple } \\
\text { and non-predefined } \\
\text { answers acceptable) }\end{array}$ & $\begin{array}{l}\text { a. greeting in passing; b. chatting with } \\
\text { neighbors; c. longer conversations with } \\
\text { neighbors; d. children playing; } \\
\text { e. activities that do not involve } \\
\text { interactions with neighbors. }\end{array}$ \\
\hline 6. & $\begin{array}{l}\text { Which of the following activities do you } \\
\text { use the entrance hall for? (multiple and } \\
\text { non-predefined answers acceptable) }\end{array}$ & $\begin{array}{l}\text { a. greeting in passing; b. chatting with } \\
\text { neighbors; c. longer conversations with } \\
\text { neighbors; d. children playing; } \\
\text { e. activities that do not involve } \\
\text { interactions with neighbors. }\end{array}$ \\
\hline 7. & $\begin{array}{l}\text { Which of the following activities would } \\
\text { you like to use entrance hall for? } \\
\text { (multiple and non-predefined } \\
\text { answers acceptable) }\end{array}$ & $\begin{array}{l}\text { a. greeting in passing; b. chatting with } \\
\text { neighbors; c. longer conversations with } \\
\text { neighbors; d. children playing; } \\
\text { e. activities that do not involve } \\
\text { interactions with neighbors. }\end{array}$ \\
\hline 8. & $\begin{array}{l}\text { How important for the quality of } \\
\text { relations between the residents do you } \\
\text { consider the appearance and } \\
\text { equipment of the circulation spaces in } \\
\text { the building? }\end{array}$ & $\begin{array}{l}\text { a. unimportant; } \\
\text { b. neither important nor unimportant; } \\
\text { c. very important. }\end{array}$ \\
\hline \multicolumn{3}{|c|}{ Common areas and rooms intended for the socialization of residents } \\
\hline 9. & $\begin{array}{l}\text { Is there a common room or an area } \\
\text { inside the MFAB intended for } \\
\text { socialization of residents? }\end{array}$ & $\begin{array}{l}\text { a. yes; } \\
\text { b. no. }\end{array}$ \\
\hline 10. & $\begin{array}{l}\text { What do you consider to be the main } \\
\text { deficiency of this common space? } \\
\text { (multiple and non-predefined } \\
\text { answers acceptable) }\end{array}$ & $\begin{array}{l}\text { a. insufficient dimensions; b. lack of } \\
\text { perceivability; c. poor natural lighting; } \\
\text { d. lack of outdoor views e. not } \\
\text { protected from the sun; } \\
\text { f. lack of equipment; g. poor } \\
\text { maintenance; h. lack of security. }\end{array}$ \\
\hline 11. & $\begin{array}{l}\text { Which of the following activities do } \\
\text { you use this common space for? } \\
\text { (multiple and non-predefined } \\
\text { answers acceptable) }\end{array}$ & $\begin{array}{l}\text { a. socializing with neighbors; b. } \\
\text { children playing; c. gardening; } \\
\text { d. activities that do not involve } \\
\text { interactions with neighbors. }\end{array}$ \\
\hline 12. & $\begin{array}{l}\text { Which of the following activities would } \\
\text { you like to use this common space for? } \\
\text { (multiple and non-predefined } \\
\text { answers acceptable) }\end{array}$ & $\begin{array}{l}\text { a. socializing with neighbors; b. } \\
\text { children playing;c. growing plants; } \\
\text { d. activities that do not involve } \\
\text { interactions with neighbors. }\end{array}$ \\
\hline 13. & $\begin{array}{l}\text { How important for the quality of } \\
\text { relations between the residents do you } \\
\text { consider the existence of this kind of } \\
\text { space within the building? }\end{array}$ & $\begin{array}{l}\text { a. unimportant; } \\
\text { b. neither important nor unimportant; } \\
\text { c. very important. }\end{array}$ \\
\hline
\end{tabular}

\section{Results}

\subsection{General Quality of Circulation Spaces}

Residents of MFABs in Niš are generally dissatisfied with the general quality of circulation spaces in buildings: $38.24 \%$ rated them as bad, and $32.30 \%$ as good (Figure 11). In the results of the 2015 survey, a slightly lower percentage of respondents rated them as 
good (30.62\%) and a significantly lower percentage as bad (29.87\%). It could be concluded that the new need to keep a distance influenced this change in results.

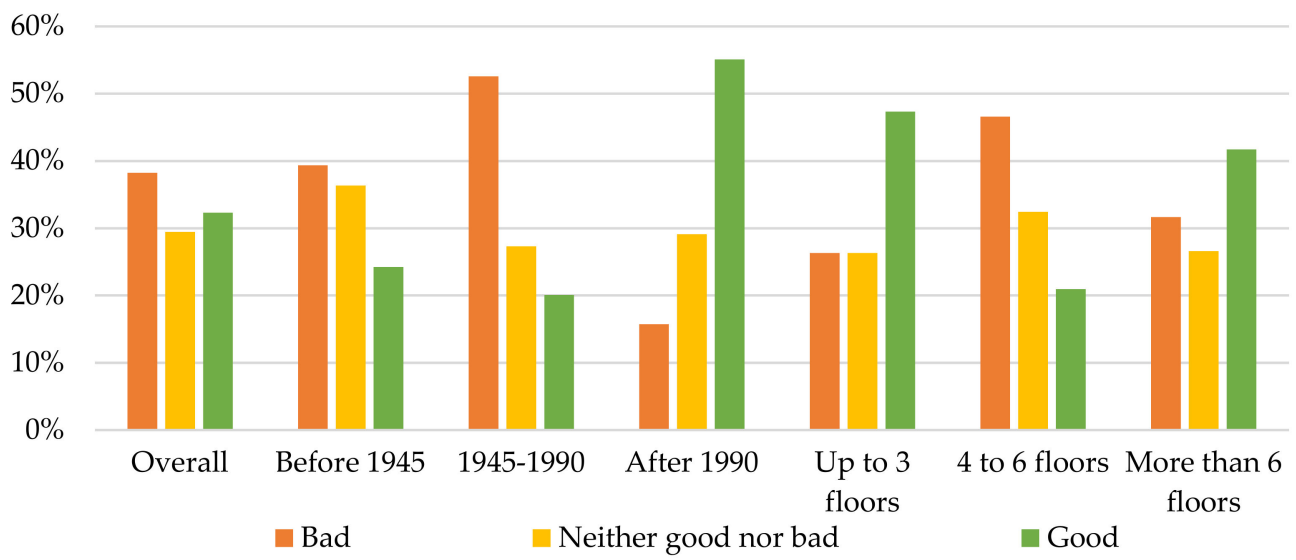

Figure 11. General quality of circulation spaces.

Depending on the period in which the buildings were built, the largest percentage of occupants who rated them as good (55.12\%) were residents of buildings built after 1990 (Figure 11). This information does not necessarily mean that the circulation spaces in the buildings from this period are the best (according to different criteria); among them are recently built buildings, which may be the reason that the general appearance of the circulation spaces is still at a satisfactory level.

In terms of the number of floors in the building, the highest marks (47.36\%) were given by the occupants of buildings with up to three floors; it is logical that, in buildings with a smaller number of floors (and therefore smaller number of users), circulation spaces are in better condition than in buildings with more floors, i.e., more users. However, the lowest grades $(20.94 \%)$ were given by the residents of buildings with four to six floors (Figure 11). The reason for this lies in the fact that a large number of buildings in this category are without elevators, and that occupants use stairs and hallways to a greater extent than is the case in buildings with elevators; due to use by a large number of residents, these spaces may be in poorer condition. Furthermore, if more encounters take place, residents cannot maintain a physical distance and therefore such a space is perceived as cramped.

When looking at the answers regarding the ownership structure, occupants who own apartments in a higher percentage $(38.62 \%)$ rate circulation spaces as good compared to those who rent their apartments $(21.64 \%)$. These results confirm the findings of some authors that users who own their apartment are generally more positive towards their residential surroundings than those who rent their apartment [82]. The highest percentage of those who rate these areas as good (36.75\%) are residents whose length of residence is more than five years, and the lowest percentage $(22.03 \%)$ are those whose length of residence is less than one year. These responses are consistent with the findings of some authors that the length of use of an apartment affects the perception of the occupants, since, over time, people develop a feeling of dwelling [83].

\subsection{Main Deficiencies of Hallways and Staircases}

The main disadvantages of hallways and staircases in buildings with centralized access are insufficient dimensions (21.85\% of responses) and poor natural lighting (15.89\%); bearing in mind that, in this type of structure, the horizontal circulation space is usually reduced only to a landing, and that, since the outbreak of the pandemic, there has been an increased need to maintain a physical distance, the former answers are expected. In gallery access buildings, where horizontal circulations are usually open and therefore well ventilated, the main deficiencies are the lack of equipment $(28.20 \%)$ and the lack of intimacy $(24.36 \%)$. In corridor access buildings, respondents again mostly complained about poor 
natural lighting (19.63\%) and insufficient dimensions (17.18\%), as well as a lack of intimacy $(16.56 \%)$ (Figure 12).

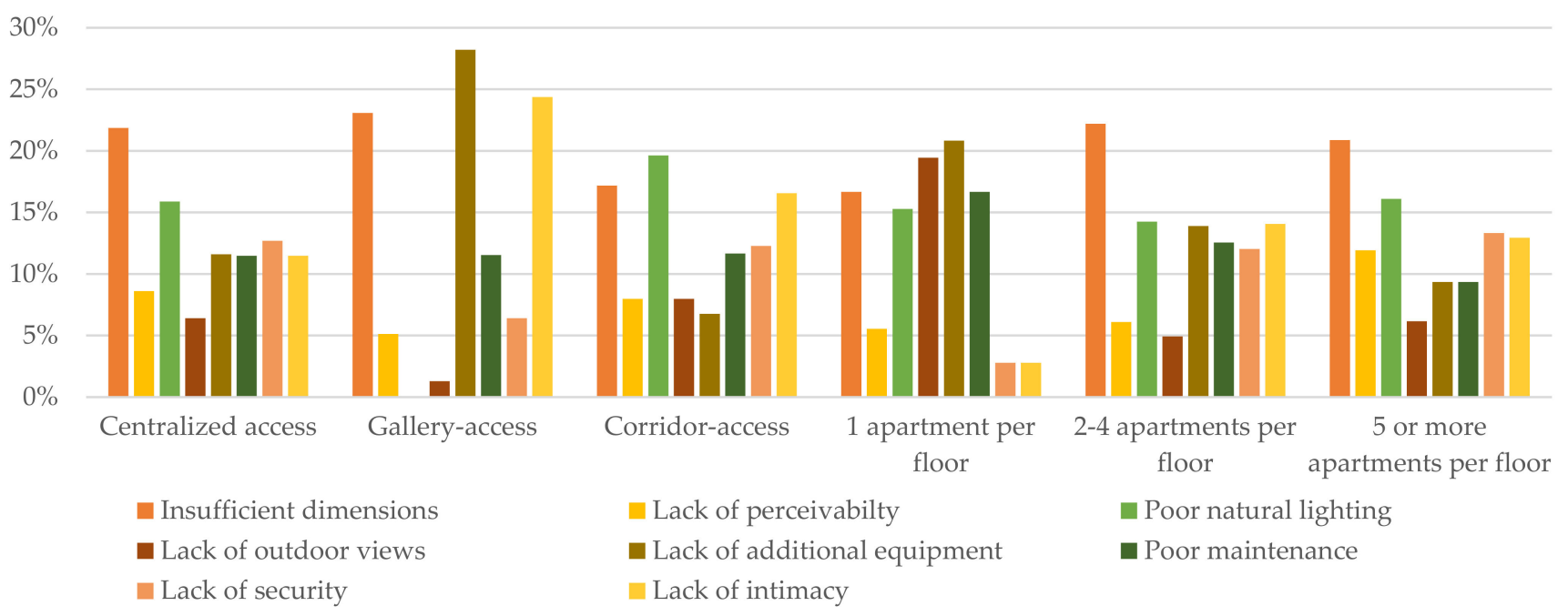

Figure 12. Main deficiencies of hallways and staircases.

Depending on the number of apartments per floor, the main deficiencies are as follows: in buildings with one apartment per floor, there is a lack of additional equipment (20.83\%) and a lack of outdoor views (19.44\%); in buildings with two to four apartments per floor, there are insufficient dimensions (22.20\%) and poor natural lighting (14.24\%); in buildings with five or more apartments per floor, besides insufficient dimensions $(20.87 \%)$ and poor natural lighting $(16.10 \%)$, there is also a lack of security $(13.32 \%)$ and lack of intimacy (12.94\%). These results indicate that, in residential schemes with a small number of apartments per floor, which are not characterized by a crowd in circulation spaces, residents recognize as the main shortcomings characteristics that are perceived as a problem in a very small percentage in schemes with multiple apartments per floor (Figure 12).

\subsection{Main Deficiencies of Entrance Halls}

The main disadvantages of the entrance halls are as follows: for the occupants of MFABs built before 1945, there is a lack of outdoor views (19.58\%); for residents of buildings from the period 1945-1990, there is poor maintenance $(19.39 \%)$ and a lack of security (17.41\%); for users of buildings built after 1990, there are insufficient dimensions (29.67\%) and poor natural lighting (19.23\%). The latter answers confirm the previously stated claim that housing construction of this period, especially during the 1990s and 2000s, is often characterized by non-compliance with norms and poorer design schemes, often to the detriment of the quality of the building's circulation spaces, and the overall quality (Figure 13).

In terms of the number of floors in the building, residents of buildings with up to three floors have the most complaints about the lack of additional equipment in the entrance halls $(20.12 \%)$ and lack of outdoor views (19.51\%), and they complain much less about the dimensions, natural lighting or maintenance. For occupants of buildings with three to six floors, there are insufficient dimensions (19.71\%) and poor natural lighting (18.07\%), while, for occupants of buildings with more than six floors, there are insufficient dimensions $(23.31 \%)$ and a lack of security $(20.54 \%)$. Among other things, the dimensions of the entrance hall are perceived depending on the number of users who pass, meet or delay in them, so it is likely that the occupants evaluate them as insufficiently large due to the fact that they cannot keep the required physical distance in them (Figure 13). 


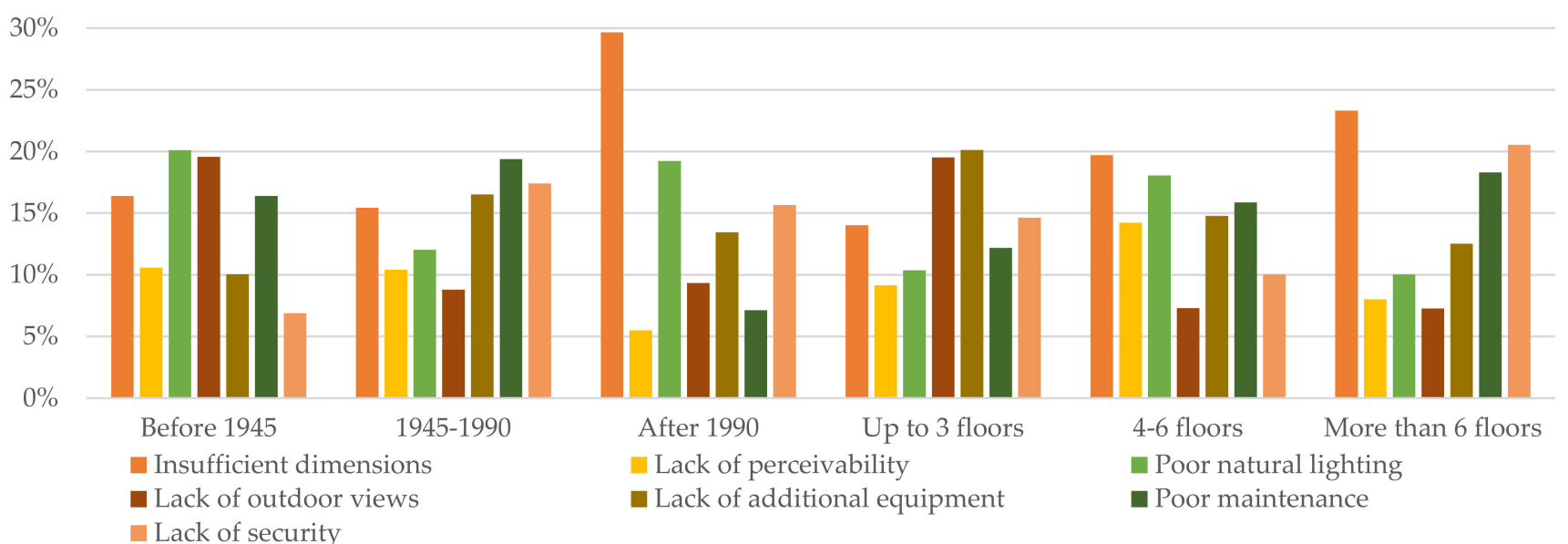

Figure 13. Main deficiencies of the entrance halls.

\subsection{Activities for Which Residents Use Hallways}

Although it could be expected that the intensity and nature of the residents' activities within the common areas of MFABs has changed due to the compulsory confinement, this may have been the case only in the earliest period of the pandemic. From the conversations with the respondents, one could conclude that residents adapted very quickly to the new conditions and returned to their usual daily activities, this time in accordance with infection prevention and control measures.

In buildings with centralized access to the apartments, as many as $33.80 \%$ of the answers referred to chatting with neighbors, $12.66 \%$ to longer conversations with neighbors and only $10.57 \%$ to children's play, which is an activity that especially gained momentum after the outbreak of the pandemic. Although it would be expected that, in buildings with gallery access, due to the characteristics attributed to them as generators of social interactions, a significantly higher percentage of responses relate to longer conversations or children's play, the truth is different. Namely, in this type of design scheme, longer conversations with neighbors constituted only $16.13 \%$ of the total number of answers and children's play constituted $14.52 \%$ (these responses do represent the highest values out of all forms of circulation spaces, but far less than expected). These data indicate that the perception of residents regarding certain questions differs from the perception of the scholars: galleries are clearly not recognized as walking paths where neighbors can converse and children play [14]. In buildings with corridor access, $8.53 \%$ of residents responses related to longer conversations with neighbors, and only $3.88 \%$ to children's play (which are certainly the lowest values on both issues, for all forms of circulation spaces, as expected).

In buildings with one apartment per floor, occupants have less contact with their neighbors in the hallways (10.53\% of responses for chatting in passing and only $8.77 \%$ for longer conversations with neighbors), but, to a much greater extent, they allow their children to play in the hallway $(15.79 \%)$, due to the fact that security and safety are usually higher. In buildings with two to four apartments per floor, the percentages of responses related to chatting and longer conversations with neighbors are much higher $(40.17 \%$ and $15.38 \%$ ); there are more users, so more encounters are generated. Although it would be expected that, in buildings with five or more apartments per floor, these percentages will be even higher, this is not the case $(33.08 \%$ and $11.03 \%)$, which indicates that the size of the social group consisting of users of two to four apartments per floor is optimal for its harmonious functioning. Moreover, a larger group of people staying indoors means a higher chance of transmitting the disease, which is an additional reason for such results.

Households with adults only chat (32.15\%) and have longer conversations with their neighbors $(8.55 \%)$ in the hallways of the MFABs the least out of all categories of households; these households are mostly composed of employed people and/or students, who have less 
time and less need for stronger connections with their neighbors. Even in the conditions of working and studying from home, this category of residents in the lowest percentage establishes stronger connections with their neighbors within the hallways. These activities are much more represented in the responses of households with small children $(39.12 \%$ and $13.61 \%$ ) and senior residents (50.00\% and 14.49\%) (Figure 14).

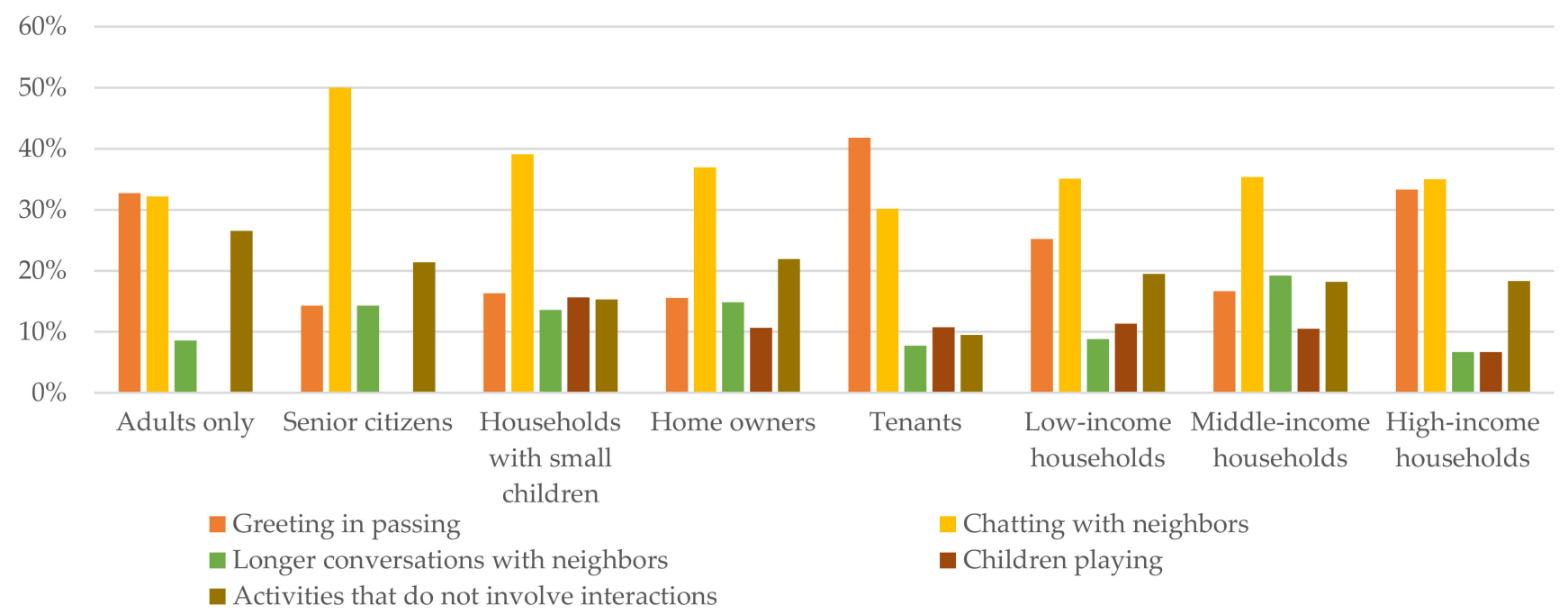

Figure 14. Activities for which residents use the hallways.

Tenants in a much higher percentage only greet neighbors in passing $(41.81 \%)$ compared to residents who own their apartment $(15.58 \%)$; they also chat much less $(30.17 \%)$ and have fewer longer conversations with their neighbors $(7.76 \%)$ than owners of apartments $(36.94 \%, 14.86 \%)$. Tenants are temporarily accommodated, so, for this reason, they do not develop stronger connections with their neighbors, while residents who own their apartments in large numbers have a permanently resolved housing issue, so they can develop stronger ties with their neighbors (Figure 14).

Longer conversations with neighbors in hallways are mostly practiced by members of middle-income households (19.23\%) and least by members of high-income households $(6.67 \%)$. Children's play in hallways is most common in low-income households $(11.34 \%)$ and least in high-income households (6.67\%). Members of high-income households in the largest percentage of all three categories only greet neighbors in passing $(33.33 \%)$. The paradigm that residents with higher incomes have more contacts with neighbors proved to be incorrect here. The reason probably lies in two facts: firstly, there is generally no housing zoning according to income status in Niš, so all income groups live dispersed throughout the city; secondly, high-income households are represented in the smallest percentage in the city and are usually surrounded by lower-income households. In such conditions, it is clear why there are no stronger neighbor ties between wealthier residents and other categories (Figure 14).

\subsection{Activities for Which Residents Would Like to Use the Hallways}

In general, it is noticeable that the occupants want less superficial contacts (greeting in passing and chatting with neighbors) and activities that do not include interactions with neighbors and far more stronger contacts in the form of longer conversations and children's play. This is particularly noticeable in corridor access structures, where the percentage of responses related to longer conversations with neighbors increases from $8.53 \%$ to $18.38 \%$; these occupants obviously hold in high regard stronger neighborhood ties, which may be due to the fact that the physical framework for this kind of contact is the least favorable in their buildings, which is particularly emphasized in the conditions of the COVID-19 pandemic. If the answers "chatting with neighbors" and "longer conversation with neighbors" were combined into one-“"socializing with neighbors" (for comparison 
with the results of the 2015 survey) - a large increase in the percentage of these responses can be seen, from $25.18 \%$ from the period before the COVID-19 pandemic to $50.46 \%$ during the pandemic. An increase is also observed in the responses related to children's play, from $7.22 \%$ to $13.64 \%$.

Moreover, there were a significant number of answers that were not predefined (these activities were not recognized by the author in the current state and were not offered in the answers to the question about the residents' preferences), related to joint activities with neighbors in these spaces (hobby, watching a game, playing cards, drinking coffee/beer, etc.). These responses were combined into one and were called joint activities, and their share in the total number of responses was $2.77 \%$ (Figure 15). The reason for the appearance of these responses can be linked with the imposed reduced mobility and the fact that the needs for social interactions are now more met within MFABs.

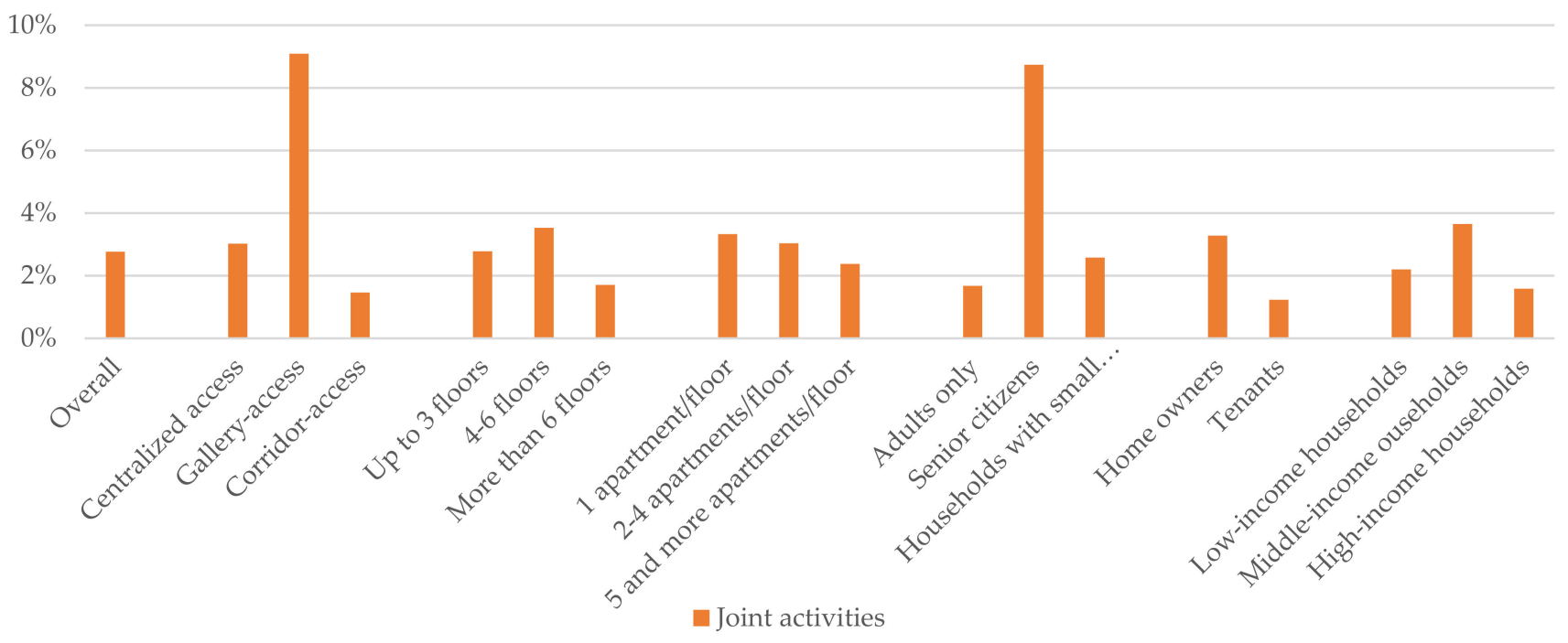

Figure 15. Residents' preferences regarding joint activities in the hallways.

Depending on the form of access to the apartments, the most answers concerning joint activities were in gallery access buildings (9.09\%) (Figure 15); this means that the occupants of these buildings, although they do not use the galleries to interact with their neighbors to the extent that might be expected, do recognize the potential that these spaces represent for strengthening social ties between neighbors and perceive them as healthy and safe enough. Households consisting of senior citizens in the largest percentage want joint activities (8.74\%) in the hallways, and households composed of exclusively adults desire these the least $(1.68 \%)$. Residents who own apartments in a higher percentage $(3.28 \%)$ want joint activities in the hallways than tenants (1.23\%) (Figure 15).

\subsection{Activities for Which Residents Use the Entrance Halls}

In terms of the number of floors in the building, the largest number of longer conversations within the entrance halls occur in buildings with four to six floors $(17.85 \%)$, which may indicate that the size of the social group in buildings of this height is optimal for its functioning as a small harmonious community and that it still does not cause dense places that would significantly increase virus transmission. In buildings lower and higher than those mentioned above, the share of these responses is between $13 \%$ and $14 \%$. Children's play in the entrance halls is most prevalent in buildings with up to three floors (9.23\%), because, in these buildings, the apartments themselves are closer to the entrance hall, so it is easier for parents to monitor their children.

When it comes to the age structure of the household, longer conversations with neighbors in entrance halls are mostly conducted by senior citizens (25.53\%). Conversely, households composed of adult members to the greatest extent only greet their neighbors 
in passing (34.15\%) and have the highest percentage of responses related to activities not involving other residents of the building (9.23\%) (Figure 16).

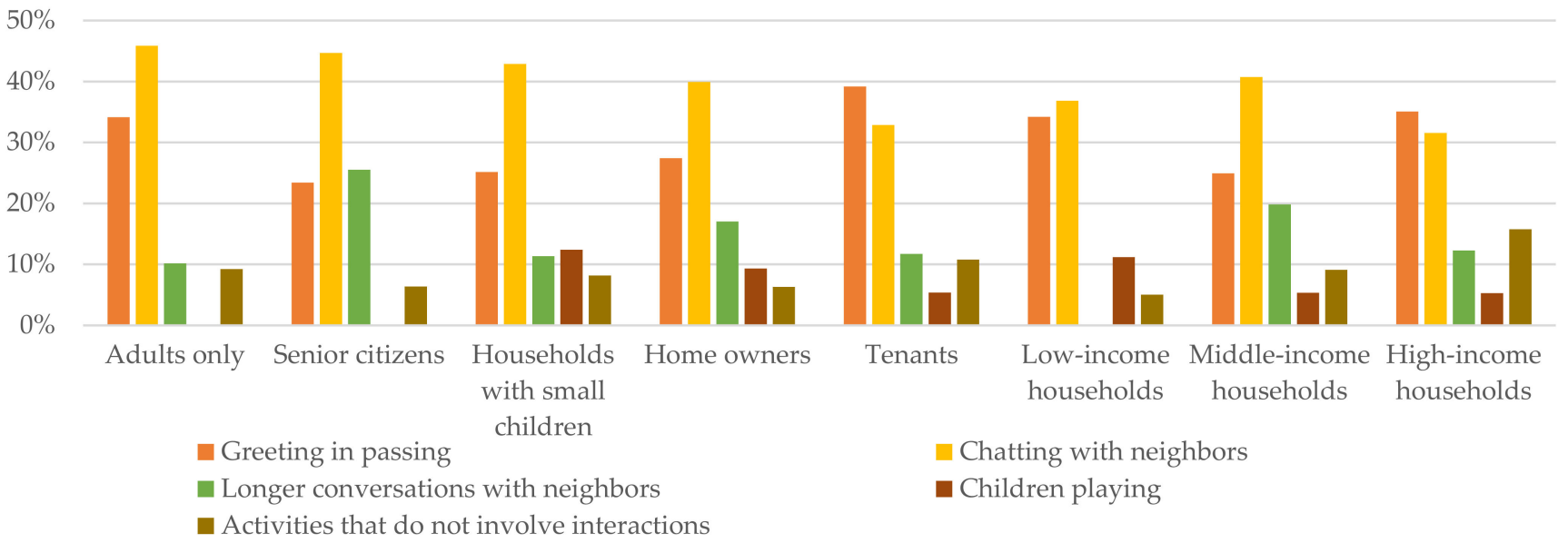

Figure 16. Activities for which residents use the entrance halls.

Residents who own their apartments practice more longer conversations with neighbors $(17.02 \%)$ and fewer activities that do not include other occupants $(6.33 \%)$ compared to those who rent their apartments $(11.71 \%$ and $10.81 \%)$. Homeowners also choose more responses related to children's play (9.34\%) than tenants (5.40\%) (Figure 16).

Members of middle-income households carry out the largest number of longer conversations within the entrance halls (19.84\%), while the least are carried out by members of high-income households (12.28\%). The latter perform most activities that do not involve other neighbors (15.79\%); this result is probably due to the fact that wealthier occupants can more easily meet their needs for social interactions outside their place of residence, even when it comes to conditions of limited mobility (Figure 16).

\subsection{Activities for Which Residents Would Like to Use the Entrance Halls}

As was the case with the hallways of the buildings, among the answers about the activities that the residents would like to perform within the entrance halls, it can be noticed that they would prefer more deeper and longer contacts with their neighbors and less superficial and short ones. Moreover, a group of activities that were not predefined appeared in the answers, which were, due to their nature, classified as joint activities. Their share in the total number of responses was $4.81 \%$ (Figure 17).

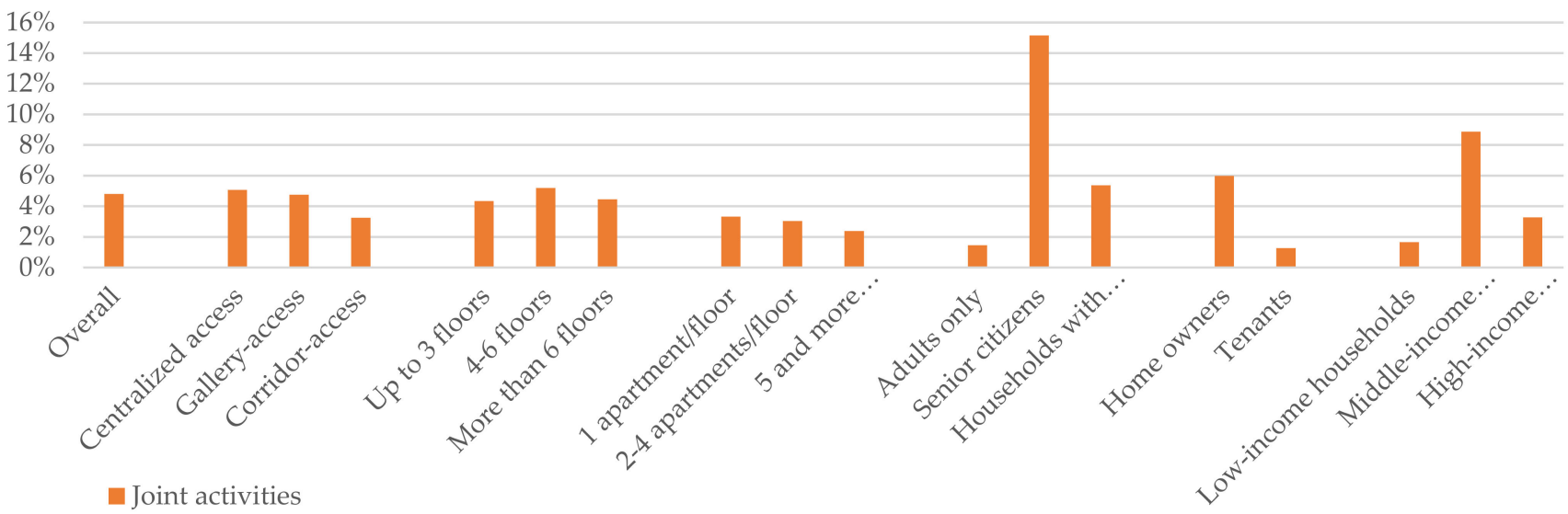

Figure 17. Residents' preferences regarding joint activities in the entrance halls.

The most answers related to joint activities appeared in buildings with four to six floors $(5.19 \%)$, which once again confirms the fact stated earlier about the optimal size 
of the social group. Households with senior citizens give as much as $15.16 \%$ of answers related to joint activities in the entrance halls, and households with adults only amounted to $1.45 \%$. More than $22 \%$ of the responses of households with small children referred to children's play in the entrance halls of buildings. Joint activities within the entrance halls made up $5.98 \%$ of the responses of occupants who owned their apartments and only $1.28 \%$ of those who rented their apartments (Figure 17).

\subsection{Importance of the Circulation Spaces for Relations between Residents}

As many as $41.08 \%$ of respondents believed that the appearance and equipment of circulation spaces are important for the quality of relations between neighbors. Compared to the results from the time before the pandemic (when only $29.38 \%$ of respondents chose this answer), a significantly higher percentage of residents consider circulating spaces important for relations between neighbors during the pandemic. Surprisingly, residents of apartments with separate entrances find them important in the largest percentage (66.66\%); as they have very few opportunities to meet neighbors and interact with them, they may better understand the importance of these spaces for socializing with other neighbors. Occupants of buildings with corridor access also recognize this importance in a large percentage $(44.45 \%)$; the fact is that dark and monotonous corridors are a very unfavorable physical environment for establishing relations between neighbors; this may contribute to the recognition of the importance that these spaces could have for the quality of relations between neighbors. Out of all the forms of circulation spaces, the occupants of gallery access buildings recognized the importance of these spaces in the smallest percentage; this confirms the findings of some authors [14] that, if a quality is present in the housing environment, residents do not consider it important and often accept it as granted, and if it does not exist, they mark it as important (Figure 18).

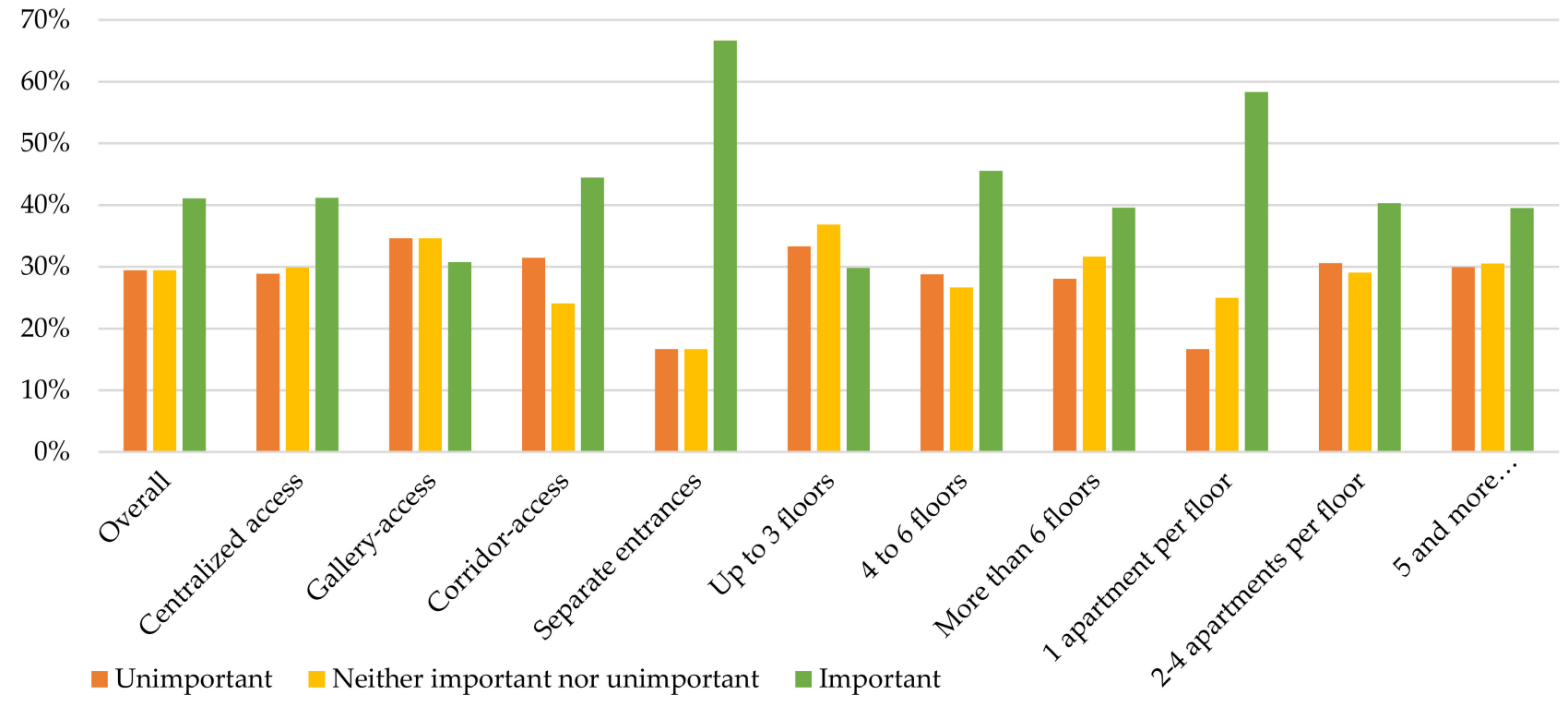

Figure 18. Residents' preferences regarding joint activities in the entrance halls.

\subsection{Common Rooms and Areas Intended for Socializing}

Only $31.27 \%$ of respondents answered that there is a common premise in their building designated for the socialization of occupants (Figure 19). Many answers stated that such premises originally existed, but that, with the consent of the majority of neighbors, their purpose was changed. Most of these premises are in buildings from the period 1945-1990 $(48.45 \%)$ and the least in buildings built before 1945 (7.58\%) (Figure 19). There were also answers stating that the residents voluntarily rearranged a certain space (hall, laundry room, etc.) for such a purpose. The adaptive reuse of underused and unused spaces within the MFABs became particularly prevalent during the COVID-19 lockdowns, because people 
needed to make a place for themselves where they could socialize outside their apartments. Nevertheless, the application of this concept contributes to the enhancement of housing conditions both in the context of the pandemic and in general.

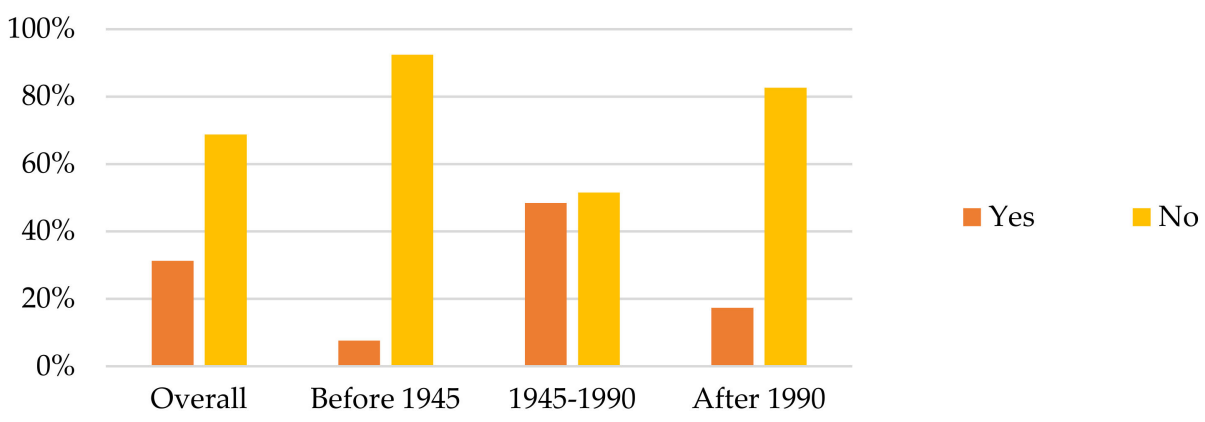

Figure 19. Common rooms and areas intended for socializing in MFABs.

\subsection{Main Deficiencies of the Common Rooms and Areas Intended for Socializing}

The main deficiency of these premises is a lack of equipment $(26.36 \%)$, which is probably the most important quality for such premises to function as spaces for socialization among neighbors, primarily meaning seating furniture, bookshelves, TVs, but also props for recreation, children's play, preparing food/drinks, etc. This is followed by poor maintenance $(18.25 \%)$, which is generally a major problem for spaces that do not have a specific owner. This is followed by insufficient natural lighting (14.07\%) and insufficient dimensions $(13.56 \%)$, which is partly due to the fact that a number of these rooms were not originally intended for the current purpose. The residents also mentioned some not predefined shortcomings (5.96\%) that related to the inadequate material selection (for equipment, walls, floors); from the perspective of the increased need for regular cleaning and disinfection of spaces where people from different households stay, the occupants recognized that certain materials are not suitable for such spaces (Figure 20).
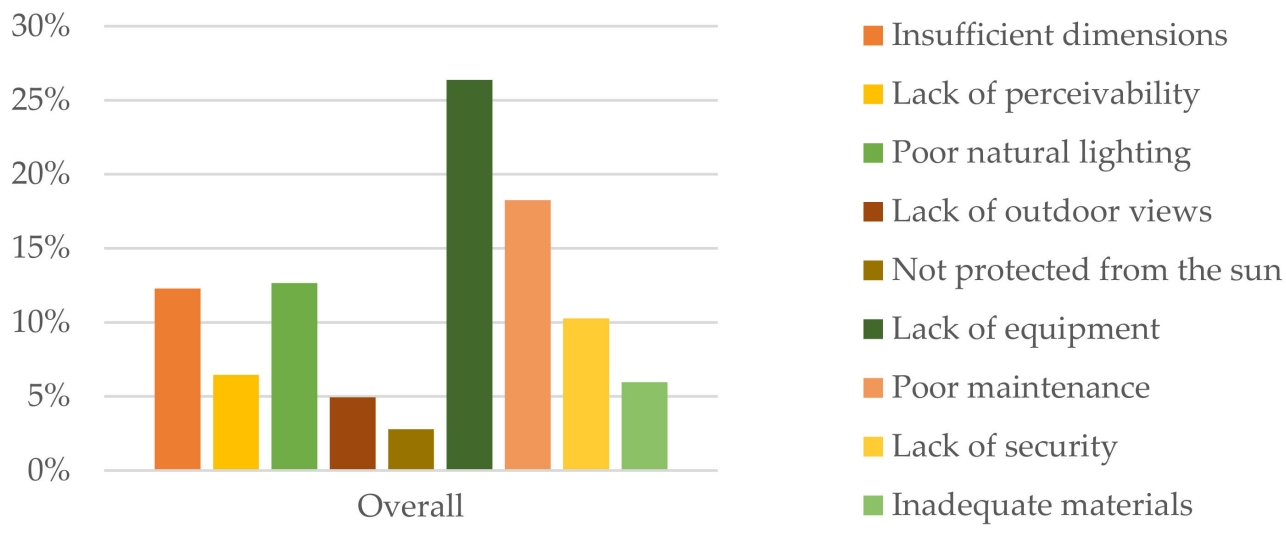

Figure 20. Main deficiencies of the common rooms and areas intended for socializing.

\subsection{Activities for Which Residents Use the Common Rooms and Areas Intended for Socializing}

Despite the fact that very few MFABs have a common room for the socialization of occupants, even where they do exist, almost a quarter of users do not use it. This percentage was even higher before the outbreak of the pandemic, and, according to the residents, mobility restrictions have contributed to greater use of these premises. Among the answers of the residents who use these spaces, $40.37 \%$ refer to spending time with and socializing with their neighbors (conversations, drinking coffee, table tennis, table football, watching television, etc.), $21.92 \%$ to children's play and $16.74 \%$ to growing plants. The imposed limited mobility and the inability to meet one's needs for socialization outside the housing facilities forced people to turn more to the use of available spaces within their housing facilities. A higher percentage of occupants who own their apartments use 
these premises for hanging out and socialization (41.84\%) than occupants who rent their apartments (33.90\%). Approximately $40 \%$ of the answers of low-income and middle-income households refer to socializing and joint activities with neighbors, while in high-income households, this percentage is lower (33.33\%) (Figure 21).

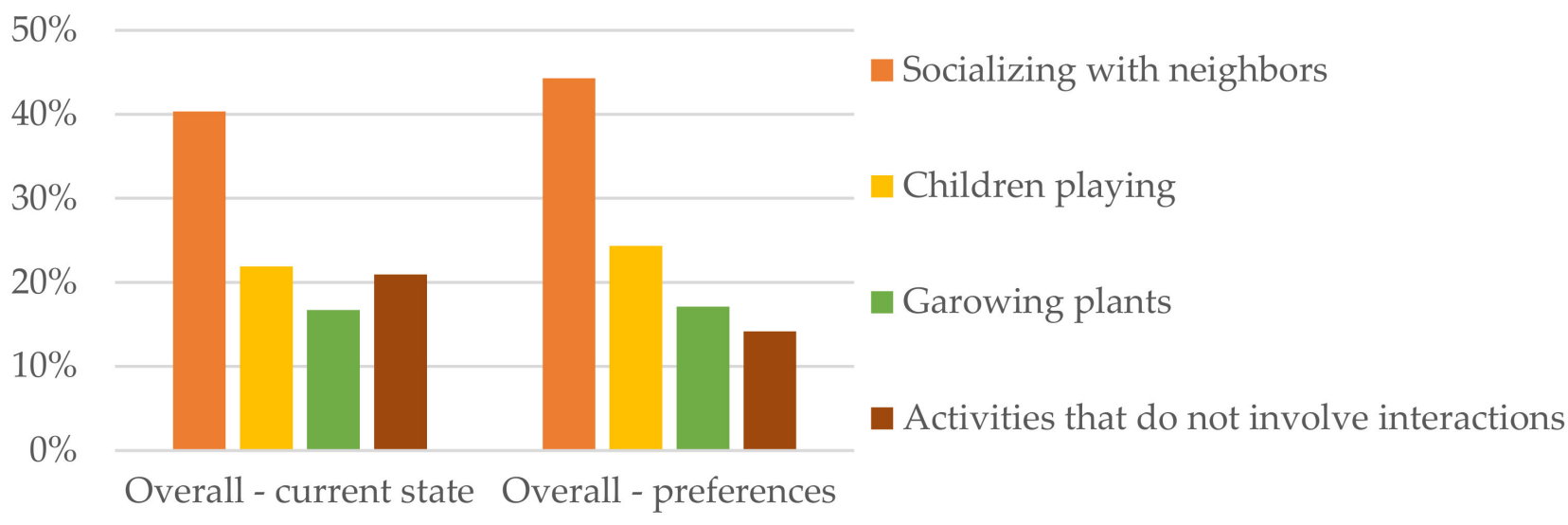

Figure 21. Comparative overview of the activities for which residents use and for which residents would like to use the common rooms and areas intended for socializing.

\subsection{Activities for Which Residents Would Like to Use the Common Rooms and Areas Intended for Socializing}

Occupants' responses to the question regarding which activities they would like to use the common rooms and areas for were characterized by an increase in the percentage in favor of socializing and joint activities (44.32\%)_-drinking coffee/beer, watching matches, sunbathing, joint hobby activities, joint winter stores preparation-in relation to the current state $(40.37 \%)$. Moreover, the percentage of responses related to children's play increased (from $21.92 \%$ to $24.37 \%$ ). These responses indicate that occupants would like to use the common premises to develop deeper and stronger ties with their neighbors, with appropriate preconditions (Figure 21).

\subsection{Importance of the Common Rooms and Areas Intended for Socializing for Relations between Residents}

Overall, $48.49 \%$ of the surveyed residents believe that the existence of a common room or area intended for socializing is important for the quality and intensity of social ties between neighbors. Living conditions during the lockdowns and compulsory confinements caused by the COVID-19 pandemic have forced the residents of MFABs to reconsider their views on the importance of common premises designed for socializing and to realize that such spaces, if adequately designed and equipped, can have a positive impact on the quality and intensity of neighbor relations. Interestingly, depending on the number of apartments per floor, residents whose apartment is the only one on the floor find them important in the largest percentage (55.56\%), which suggests that these occupants have less interaction with their neighbors and believe that the existence of such a premise in the building significantly enhanced and strengthened the social ties between neighbors. A higher percentage of occupants who own apartments consider the existence of these spaces important $(47.08 \%)$ compared to tenants $(27.78 \%)$. Occupants who have lived in their apartment for less than one year recognize the importance of these premises in the lowest percentage $(30 \%)$, and those who have lived in their apartment for more than five years the most $(47.40 \%)$ (Figure 22$)$. 


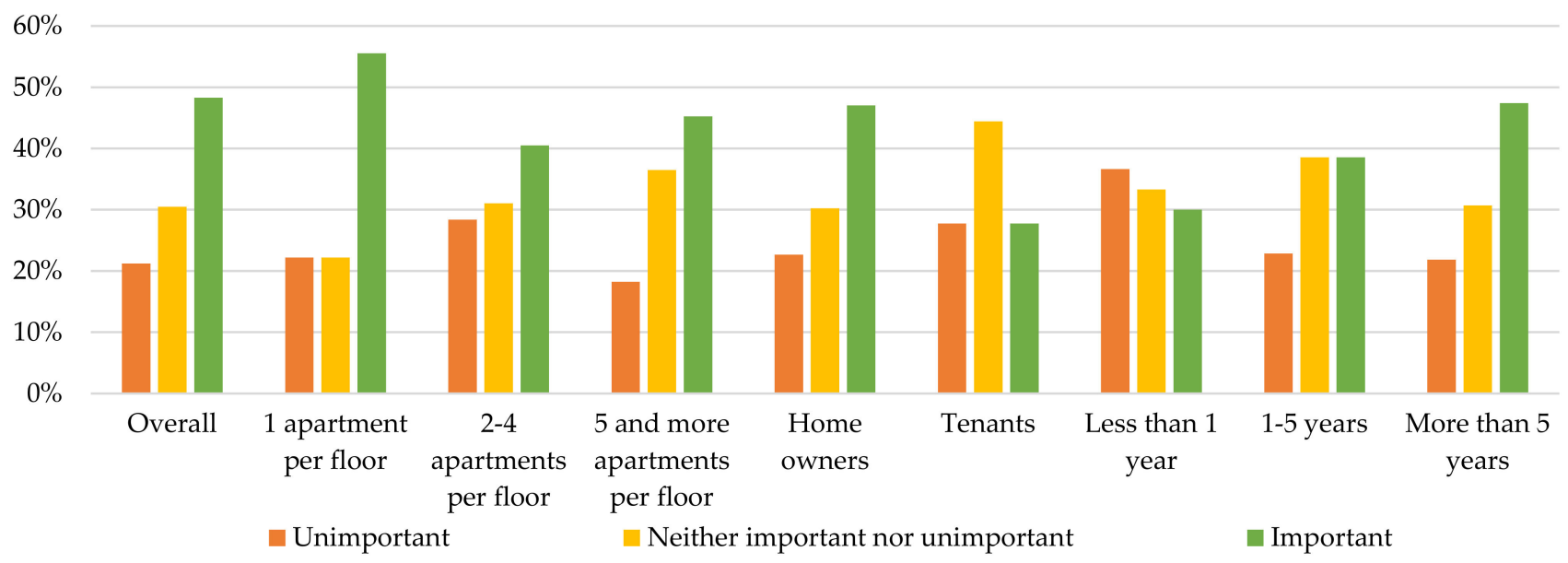

Figure 22. Importance of the common rooms and areas intended for socializing for relations between residents.

\section{Discussion}

An analysis of the survey results leads to three groups of findings. Although the questions did not strictly and exclusively address the conditions caused by the COVID19 pandemic, residents' responses were largely influenced by the new COVID-19 reality, and comparable results from pre-pandemic research confirm that COVID-19 has significantly influenced residents' perceptions and preferences regarding their relations with their neighbors. The first group of findings relates to an assessment of the current condition of common spaces in MFABs in Niš, as an architectural framework for establishing interactions between neighbors. The second group reveals how much residents recognize the importance of common spaces in buildings for the development of social ties. The third group concerns the wishes of the residents regarding common spaces and the establishment and development of neighborhood ties.

Firstly, the impression is that the condition of common spaces in MFABs from the aspect of convenience for establishing neighbor connections is at an unsatisfactory level. Many residents describe the general condition of circulation spaces as poor and one can notice that respondents are stricter in grading this aspect in the context of COVID-19. The main disadvantages, both for hallways and entrance halls-insufficient dimensions, lack of natural lighting and lack of security — show that when designing these spaces, architects are guided solely by their primary purpose-passing. Moreover, when designing these spaces, architects could have not foreseen the needs that would arise due to the outbreak of a pandemic. Hallways are designed with the minimum dimensions defined by norms (sometimes even less), often without adequate natural lighting. The potential for these spaces to represent a physical framework for socializing among neighbors is obviously not considered in most cases. Even in gallery access buildings, horizontal circulations are designed so that they cannot accept any additional activity besides the basic one. Entrance halls, acting as a transitional space between outdoor and indoor areas, are often reduced to an air-trap space with mailboxes. With minimal dimensions, made of low-quality and/or unattractive materials, without any additional equipment, such spaces cannot be a pleasant space for spontaneous and intentional social interactions between neighbors. Speaking from the perspective of infection prevention and control, these spaces usually do not provide safe and healthy conditions for the progress of neighbor ties; this refers to their dimensions, natural lighting and ventilation and the use of easily washable materials.

When it comes to common rooms and spaces intended for the socialization of neighbors, they do not exist in most MFABs in Niš. If they do exist, the main downsides are the lack of equipment that would encourage the development of social connections among users and poorly organized maintenance of the space. Users also consider as disadvantages if such rooms are not large enough to keep a physical distance, as well as if they have equip- 
ment or surfaces made of materials that cannot easily be sanitized. In some buildings, such spaces were provided by the design, but their purpose was changed during exploitation. Moreover, in some MFABs, during lockdowns but also before the pandemic, the residents organized themselves and made a space for socializing from a room intended for some other purpose.

Secondly, the survey shows that residents recognize the importance of common spaces in MFABs for developing social relationships among users; they also acknowledge that the limited mobility during the pandemic largely led to such an attitude (results from the survey conducted in 2015 also confirm these findings). It is noticeable that occupants give a lower rating to a particular quality of common spaces if it is already present (they take it for granted) and give a higher rating to a quality if it is missing. For example, the occupants of the corridor access buildings, much more than the occupants of the gallery access ones, recognize the importance of horizontal circulations in the building for the development of neighborhood connections, even though the corridors are far less suitable for this. Likewise, even if there is a space in an MFAB intended exclusively for socializing, a quarter of respondents never use it; the reasons may be different and do not necessarily refer to the objective characteristics of the space, but it may be that the residents themselves do not want to socialize with their neighbors.

Thirdly, in order for the common areas of the MFAB to represent a suitable architectural framework for strengthening social ties, the residents above all want them to be appropriately dimensioned (preferably larger than defined by the norms), healthy and safe, with natural lighting. These are the qualities that are expected in the hallways, staircases and entrance halls, as well as in the premises for socializing. Although these characteristics may have been emphasized as a result of the users' need to protect themselves from the disease transmission, achieving these qualities would contribute to a significant improvement of common spaces and encourage the development of neighborhood ties, and they are in line with the findings of some research on possible solutions to improve the existing built environment after the pandemic. Appropriate maintenance is also one of the most important qualities of these spaces. This includes, in particular, the possibility of frequent natural ventilation, the use of materials for walls and floors that can be easily and quickly cleaned and sanitized, as well as the use of equipment that has easily washable surfaces. The existence of equipment is especially desirable in rooms and areas that are intended particularly for the socialization of users. The perceivability of these spaces and a pleasant view to the outside are desirable but not necessary characteristics. The concept of urban gardening, which has not yet taken root in Serbia, is quite completely unknown to the residents, so the desire for this activity is very low so far. The assumption that households with small children and seniors have more needs for common spaces in which they can interact with other occupants of the building was confirmed. The same applies to residents who own their apartments, as well as to residents whose length of residence is longer than five years. Members of middle-income households showed the greatest affinity for socializing with their neighbors out of all household categories.

\section{Conclusions}

In order to strengthen social cohesion and create a sustainable social community within MFABs, certain design guidelines and recommendations for improving and redefining standards that regulate housing construction can be singled out by combining proven design experiences and scientific knowledge on the one hand, and survey results on the other. As life amid the COVID-19 pandemic has already become a new reality, the design requirements for MFABs need to be adapted to these new conditions. Therefore, design measures that would contribute to maximizing the prevention and protection against coronavirus should also be considered and implemented to an extent that will contribute to the overall improvement of housing quality.

The design approach to common spaces in MFABs would include some of the following possibilities: (1) the entrance hall to the building should be clearly articulated, 
perceivable, with natural lighting and larger than the minimum defined by the norms; providing a seating area within the entrance hall would significantly contribute to the creation of a pleasant space that could have an additional purpose in addition to the basic one [43]; providing a washbasin or toilet next to the entrance hall would be essential from the perspective of preventing the entry of various pathogens and would be a permanently useful solution; (2) hallways in buildings should have good natural lighting and ventilation, and with a possible outside view; widening of horizontal circulation spaces would ensure an adequate level of physical distancing during the pandemic, and would also encourage users to communicate and perform joint activities [23,45,46]; (3) it is desirable to provide a room or an area that the occupants would use solely for socializing; equipping and dimensioning of this space depends on the type of planned activities and its position must not violate privacy or be a nuisance to residents; (4) it is advisable to plan open common areas within the MFABs where neighbors could talk to one another or where children could play; if the design envisages a flat roof on an MFAB, it is advisable that at least one part of it be constructed as a terrace that can be used by all occupants of the building; such spaces, equipped with appropriate furniture, can be very attractive places that residents would like to use for individual and joint activities; (5) providing urban gardens on roofs can further contribute to connecting neighbors and creating strong social cohesion, as well as stimulating residents to grow food in periods of isolation [20,43]; (6) materials used for floor, wall and ceiling coverings, as well as materials used for equipment, should have a shorter residence time for viruses and be easy to clean [23,43]; (7) favoring simple and minimalist design schemes for common spaces (without unnecessary details, decorations, carpets, curtains, etc.) could help to reduce the accumulation of viruses in them and benefits such as lower costs and easier maintenance would contribute to overall sustainability [23]; (8) in order to form a social group (at the level of the floor, as well as at the level of the whole building) that is functional, the optimal number of floors is up to five, and the optimal number of apartments per floor is two to four; limiting the number of floors and apartments in the building will also contribute to limiting the possibility of disease transmission and better organization of building maintenance.

Although designing circulation spaces as places suitable for socializing neighbors would be useful for the overall residential quality and social sustainability, regulations in the field of housing construction generally do not recognize this opportunity, so architects and investors are not stimulated to design them in this way. Although, from the perspective of creating an architectural framework for interactions between users, as well from the perspective of keeping physical distance, it would be desirable for the circulation spaces in the building to be larger than defined, it is not logical to impose them as mandatory. What could be regulated is the formula for the calculation of fees and taxes that investors are due to pay to the authorities. Namely, the fees and taxes are now calculated per square meter for the total surface area of the building, meaning that the same amount has to be paid for every square meter of common space in the building, which cannot be sold, thus increasing costs and reducing profits for investors. In this regard, it is clear why investors decide almost unanimously on the minimum dimensions and surface areas defined by the norms when it comes to common spaces in the building. Calculating the fee according to the useful net area of the building or introducing a corrective factor to reduce the calculated area of common spaces of the building would stimulate and encourage investors to offer innovative solutions for circulation and other common spaces in MFABs, in cooperation with architects. This would encourage the design of enlarged entrance halls, which could accommodate some additional activities besides the basic one, wider parts of horizontal circulations that can be used for socializing and various joint activities of residents, and common premises for entertainment and leisure, while providing a healthier environment. In this way, the quality of the entire design would be significantly improved, which could increase the economic value of the apartments.

Having in mind the results of this research, a future study could analyze changes in the intensity, quality and location of social interactions among neighbors within MFABs 
before the outbreak of the COVID-19 pandemic, during lockdown periods and during the later stages of the pandemic. Furthermore, some future research could deal with specific functional organizations of common areas of MFABs, the impact of different organizations on the quality and intensity of social interactions and surveying occupants about their needs and wishes about certain spatial arrangements of common spaces.

Funding: This research received no external funding.

Institutional Review Board Statement: Not applicable.

Informed Consent Statement: Not applicable.

Data Availability Statement: Not applicable.

Conflicts of Interest: The author declares no conflict of interest.

\section{References}

1. Kleinhans, R. Social implications of housing diversification in urban renewal: A review of recent literature. J. Hous. Built Environ. 2004, 19, 367-390. [CrossRef]

2. Bektaş, Y.; Taşan-Kok, T. Love thy neighbor? Remnants of the social-mix policy in the Kolenkit neighborhood, Amsterdam. J. Hous. Built Environ. 2020, 35, 743-761. [CrossRef]

3. Larcombe, D.; Etten, E.V.; Logan, A.; Prescott, S.L.; Horwitz, P. High-Rise Apartments and Urban Mental Health-Historical and Contemporary Views. Challenges 2019, 10, 34. [CrossRef]

4. Nguyen, L.; van den Berg, P.; Kemperman, A.; Mohammadi, M. Where do People Interact in High-Rise Apartment Buildings? Exploring the Influence of Personal and Neighborhood Characteristics. Int. J. Environ. Res. Public Health 2020, 17, 4619. [CrossRef] [PubMed]

5. Muhuri, S.; Basu, C. Interactional Spaces of a High-Rise Group Housing Complex and Social Cohesion of its Residents: Case Study from Kolkata, India. J. Hous. Built Environ. 2021, 36, 781-820. [CrossRef]

6. Gifford, R. The Consequences of Living in High-Rise Buildings. Arch. Sci. Rev. 2007, 50, 2-17. [CrossRef]

7. Filipovič Hrast, M.; Dolničar, V. Sense of Community and the Importance of Values: Comparison of Two Neighborhoods in Slovenia. J. Urban Aff. 2012, 34, 317-336. [CrossRef]

8. Hirvonen, J.; Lilius, J. Do neighbour relationships still matter? J. Hous. Built Environ. 2019, 34, 1023-1041. [CrossRef]

9. Kearns, A.; Whitley, E.; Mason, P.; Bond, L. 'Living the High Life'? Residential, Social and Psychosocial Outcomes for High-Rise Occupants in a Deprived Context. Hous. Stud. 2012, 27, 97-126. [CrossRef]

10. Bee, A.S.; Im, L.P. The provision of vertical social pockets for better social interaction in high-rise living. Plan. Malays. J. 2016, 4, 163-180.

11. Evans, G.W.; Wels, N.M.; Moch, A. Housing and Mental Health: A Review of the Evidence and a Methodological and Conceptual Critique. J. Soc. Issues 2003, 59, 475-500. [CrossRef]

12. Dempsey, N.; Brown, C.; Bramley, G. The key to sustainable urban development in UK cities? The influence of density on social sustainability. Prog. Plann. 2012, 77, 89-141. [CrossRef]

13. Méndez, M.L.; Otero, G.; Link, F.; Morales, E.L.; Gayo, M. Neighbourhood cohesion as a form of privilege. Urban Stud. 2021, 58, 1691-1711. [CrossRef]

14. Stoiljković, B. Could House-Like Apartments Improve the Residential Quality of a City? The Case of Niš, Serbia. J. Hous. Built Environ. 2020, 35, 375-396. [CrossRef]

15. Guest, A.M.; Wierzbicki, S.K. Social Ties at the Neighborhood Level. Urban Aff. Rev. 1999, 35, 92-111. [CrossRef]

16. Völker, B.; Flap, H. Sixteen Million Neighbors-A Multilevel Study of the Role of Neighbors in the Personal Networks of the Dutch. Urban Aff. Rev. 2007, 43, 256-284. [CrossRef]

17. Kearns, A.; Forrest, R. Social cohesion and multilevel urban governance. Urban Stud. 2000, 37, 995-1017. [CrossRef]

18. Smets, P.; Kreuk, N. Together or separate in the neighbourhood?: Contacts between natives and Turks in Amsterdam. Open Urban Stud. J. 2008, 1, 35-47. [CrossRef]

19. Aresta, M.; Salingaros, N.A. The Importance of Domestic Space in the Times of COVID-19. Challenges 2021, 12, 27. [CrossRef]

20. Tokazhanov, G.; Tleuken, A.; Guney, M.; Turkyilmaz, A.; Karaca, F. How is COVID-19 Experience Transforming Sustainability Requirements of Residential Buildings? A Review. Sustainability 2020, 12, 8732. [CrossRef]

21. Zetterberg, L.; Santosa, A.; Ng, N.; Karlsson, M.; Eriksson, M. Impact of COVID-19 on Neighborhood Social Support and Social Interactions in Umeå Municipality, Sweden. Front. Sustain. Cities 2021, 3, 685737. [CrossRef]

22. Dietz, L.; Horve, P.F.; Coil, D.A.; Fretz, M.; Eisen, J.A.; Van Den Wymelenberg, K. 2019 Novel Coronavirus (COVID-19) Pandemic: Built Environment Considerations to Reduce Transmission. Msystems 2020, 5, e00245-20. [CrossRef] [PubMed]

23. Pinheiro, M.D.; Luís, N.C. COVID-19 Could Leverage a Sustainable Built Environment. Sustainability 2020, 12, 5863. [CrossRef]

24. Galster, G. On the Nature of Neighborhood. Urban Stud. 2001, 38, 2111-2124. [CrossRef] 
25. Cheung, C.; Leung, K. Neighborhood homogeneity and cohesion in sustainable community development. Habitat Int. 2011, 35, 564-572. [CrossRef]

26. Weijs-Perrée, M.; Berg, P.V.D.; Arentze, T.; Kemperman, A. Social networks, social satisfaction, and place attachment in the neighborhood. Region 2017, 4, 133-151. [CrossRef]

27. Meegan, R.; Mitchell, A. "It's Not Community Round Here, It's Neighbourhood": Neighbourhood Change and Cohesion in Urban Regeneration Policies. Urban Stud. 2001, 38, 2167-2194. [CrossRef]

28. Eykelbosh, A. COVID-19 Precautions for Multi-Unit Residential Buildings. 2020. Available online: https://ncceh.ca/sites/ default/files/COVID-19\%20Precautions\%20for\%20Multiunit\%20Residential\%20Buildings\%20-\%20March\%2031\%202020.pdf (accessed on 3 November 2021).

29. Everyone Included: Social Impact of COVID-19. 2020. Available online: https://www.un.org/development/desa/dspd/ everyone-included-covid-19.html (accessed on 1 November 2021).

30. Granovetter, S. The Strength of Weak Ties. Am. J. Sociol. 1973, 78, 1360-1380. [CrossRef]

31. Campbell, K.E.; Lee, B.A. Sources of Personal Neighbor Networks: Social Integration, Need, or Time? Soc. Forces 1992, 70, 1077-1100. [CrossRef]

32. Blokland, T.; Nast, J. From Public Familiarity to Comfort Zone: The Relevance of Absent Ties for Belonging in Berlin's Mixed Neighbourhoods. Int. J. Urban Reg. 2014, 38, 1142-1159. [CrossRef]

33. Holland, C.; Clark, A.; Katz, J.; Peace, S. Social Interactions in Urban Public Places; Policy Press: Bristol, UK, 2007.

34. Forrest, R.; Kearns, A. Social Cohesion, Social Capital and the Neighborhood. Urban Stud. 2001, 38, 2125-2143. [CrossRef]

35. Xiao, Y.; Miao, S.; Sarkar, C.; Fan, L.; Li, Z. Do neighborhood ties matter for residents' mental health in affordable housing: Evidence from Guangzhou, China. Cities 2020, 100, 102666. [CrossRef]

36. Hoogland, C. Semi-Private Zones As a Facilitator of Social Cohesion; Catholic University of Nijmegen: Nijmegen, The Netherlands, 2000.

37. Zangger, C. Help Thy Neighbor. Neighborhood Relations, Subjective Well-Being, and Trust during the COVID-19 Pandemic. SocArXiv 2021. [CrossRef]

38. Gehl, J. Life Between Buildings-Using Public Space; Island Press: Washington, DC, USA, 2011.

39. Ebner, P.; Klaffke, J. Living Streets: Access Galleries in Residential Buildings; Springer: Vienna, Austria, 2009.

40. Ghazali, M.; Davis, M.P.; Ghazali, A.M.; Bajunid, A. The “sky Neighborhood” Layout. CTBUH J. 2014, 2, 40-47.

41. OECD Policy Responses to Coronavirus (COVID-19). Cities Policy Responses. Available online: https://www.oecd.org/ coronavirus/policy-responses/cities-policy-responses-fd1053ff/ (accessed on 30 December 2021).

42. Hamidi, S.; Sabouri, S.; Ewing, R. Does Density Aggravate the COVID-19 Pandemic?: Early Findings and Lessons for Planners. J. Am. Plann. Assoc. 2020, 86, 495-509. [CrossRef]

43. Capolongo, S.; Rebecchi, A.; Buffoli, M.; Appolloni, L.; Signorelli, C.; Fara, G.M.; D'Alessandro, D. COVID-19 and Cities: From Urban Health Strategies to the Pandemic Challenge. A Decalogue of Public Health Opportunities. Acta Biomed. 2020, 91, 13-22. [PubMed]

44. Honey-Rosés, J.; Anguelovski, I.; Chireh, V.K.; Daher, C.; van den Bosch, C.K.; Litt, J.S.; Mawani, V.; McCall, M.K.; Orellana, A.; Oscilowicz, E.; et al. The Impact of COVID-19 on Public Space: An Early Review of the Emerging Questions-Design, Perceptions and Inequities. Cities Health 2020. [CrossRef]

45. Amerio, A.; Brambilla, A.; Morganti, A.; Aguglia, A.; Bianchi, D.; Santi, F.; Costantini, L.; Odone, A.; Costanza, A.; Signorelli, C.; et al. COVID-19 Lockdown: Housing Built Environment's Effects on Mental Health. Int. J. Environ. Res. Public Health 2020, 17, 5973. [CrossRef] [PubMed]

46. Florida, R.; Rodriguez-Pose, A.; Storper, M. Cities in a Post-COVID World. Urban Stud. 2021. [CrossRef]

47. Williams, J. Designing Neighbourhoods for Social Interaction: The Case of Cohousing. J. Urban Des. 2005, 10, 195-227. [CrossRef]

48. Levitt, D. The Housing Design Handbook—A Guide to Good Practice; Routledge: Abingdon, UK, 2010.

49. Knežević, G. Apartment Buildings; Tehnička Knjiga: Zagreb, Croatia, 1989. (In Croatian)

50. Ebner, P.; Herrmann, E.; Hollbacher, R.; Kuntsher, M.; Wietzorrek, U. Typology +—Innovative Residential Architecture; Birkhäuser: Basel, Switzerland, 2010.

51. Sherwood, R. Modern Housing Prototypes; Harvard University Press: Cambridge, MA, USA, 2001.

52. Forster, W. Housing in the 20th and 21st Century; Prestel: Munchen, Germany, 2006.

53. Stanković, D. Haustors and common areas of apartment buildings in market conditions. In Multi-Storey Buildings with Apartments for the Market; Ilić, D., Ed.; Prosveta: Niš, Serbia, 1997. (In Serbian)

54. Rulebook on Conditions and Norms for Designing Residential Buildings and Apartments; No. 74/2015 and 82/2015; Official Gazette of the Republic of Serbia: Belgrade, Serbia, 2015. (In Serbian)

55. Quaglio, C.; Todella, E.; Lami, I.M. Adequate Housing and COVID-19: Assessing the Potential for Value Creation through the Project. Sustainability 2021, 13, 10563. [CrossRef]

56. Coley, R.L.; Kuo, F.E.; Sullivan, W.C. Where does community grow? The social context created by nature in urban public housing. Environ. Behav. 1997, 29, 468-494. [CrossRef]

57. Krellenberg, K.; Welz, J.; Reyes-Päcke, S. Urban green areas and their potential for social interaction-A case study of a socioeconomically mixed neighbourhood in Santiago de Chile. Habitat Int. 2014, 44, 11-21. [CrossRef]

58. Barbosa, O.; Tratalos, J.; Armsworth, P.; Davies, R.; Fuller, R.; Johnson, P. Who benefits from access to green space? A case study from Sheffield, UK. Landsc. Urban Plan. 2007, 83, 187-195. [CrossRef] 
59. Zhu, J.; He, B.J.; Tang, W.; Thompson, S. Community blemish or new dawn for the public realm? Governance challenges for self-claimed gardens in urban China. Cities 2020, 102, 102750. [CrossRef]

60. Glover, T.D. Healthy Garden Plots? Harvesting Stories of Social Connectedness from Community Gardens. Int. J. Environ. Res. Public Health 2021, 18, 5747. [CrossRef] [PubMed]

61. Glennie, C. Growing Together: Community Coalescence and the Social Dimensions of Urban Sustainability. Sustainability 2020, 12, 9680. [CrossRef]

62. Census of Population, Households and Dwellings in the Republic of Serbia; Statistical Office of the Republic of Serbia: Belgrade, Serbia, 2011. (In Serbian)

63. Republic Hydrometeorological Service of Serbia. Available online: http://www.hidmet.gov.rs/ciril/meteorologija/stanica_sr. php?moss_id=13388 (accessed on 2 January 2022).

64. Lukić, M.; Filipović, D.; Pecelj, M.; Crnogorac, L.; Lukić, B.; Divjak, L.; Lukić, A.; Vučićević, A. Assessment of Outdoor Thermal Comfort in Serbia's Urban Environments during Different Seasons. Atmosphere 2021, 12, 1084. [CrossRef]

65. Petrović, V. Development and Typologies of Multi-Family Housing in Niš from 1918 to the Present. Ph.D. Thesis, Faculty of Civil Engineering and Architecture, University of Niš, Niš, Serbia, 18 October 2021. (In Serbian).

66. Zeković, S.; Maričić, T.; Cvetinović, M. Transformation of Housing Policy in a Post-Socialist City: Example of Belgrade. In Regulating the City: Contemporary Urban Housing Law; Sidoli, J., Vols, M., Kiehl, M.N.F., Eds.; Eleven: The Hague, The Netherlands, 2017; pp. 41-64.

67. Marcuse, P. Privatization and its Discontent: Property Rights in Land and Housing in the Transition in Eastern Europe. In Cities after Socialism: Urban and Regional Change and Conflict in Post-Socialist Societies; Andrusz, G., Harloe, M., Szelenyi, I., Eds.; Blackwell: Oxford, UK, 1996; pp. 119-191.

68. Harvey, D. A Brief History of Neoliberalism; Oxford University Press: New York, NY, USA, 2005.

69. Vilenica, A. Contradictions and Antagonisms in (Anti-) Social(ist) Housing in Serbia. ACME Int. J. Crit. Geogr. 2019, 18, 1261-1282.

70. Svirčić Gotovac, A. Effects of the Housing Privatization Process in Post-Socialist Croatia. Geoadria 2020, 25, 151-176. [CrossRef]

71. Stoychev, K. The Multiplication of Inherited Defects and Its Impact on the Emergence of New Spatial Conflicts. Evidences from Post-socialist Sofia. In Spatial Conflicts and Divisions in Post-Socialist Cities; Mihaylov, V., Ed.; Springer: Cham, Switzerland, 2020; pp. 191-209.

72. Manahasa, E.; Manahasa, O. Nostalgia for the Lost Built Environment of a Socialist City: An Empirical Study in Post-Socialist Tirana. Habitat Int. 2022, 119, 102493. [CrossRef]

73. Sendi, R.; Kerbler, B. The Evolution of Multifamily Housing: Post-Second World War Large Housing Estates versus Post-Socialist Multifamily Housing Types in Slovenia. Sustainability 2021, 13, 10363. [CrossRef]

74. Soaita, A.M.; Dewilde, C. A Critical-Realist View of Housing Quality within the Post-Communist EU States: Progressing towards a Middle-Range Explanation. Hous. Theory Soc. 2019, 36, 44-75. [CrossRef]

75. Tournois, L.; Rollero, C. "Should I Stay or Should I go?" Exploring the Influence of Individual Factors on Attachment, Identity and Commitment in a Post-Socialist City. Cities 2020, 102, 102740. [CrossRef]

76. Tolloczko, B. The Structure of Relations Among Neighbours in Croatia. Colloq. Humanist. 2015, 4, 125-133. [CrossRef]

77. Filipović, M. Influences on the Sense of Neighborhood. Case of Slovenia. Urban Aff. Rev. 2008, 43, 718-732. [CrossRef]

78. Guest, A.M.; Cover, J.K.; Matsueda, R.L.; Kubrin, C.E. Neighborhood Context and Neighboring Ties. City Community 2006, 5, 363-385. [CrossRef]

79. Whitzman, C. Creating Child-Friendly Living Environments in Central Cities: Vertical Living Kids. In Geographies of Children and Young People; Freeman, C., Tranter, P., Skelton, T., Eds.; Springer: Singapore, 2015; Volume 12.

80. Bailey, N.; Kearns, A.; Livingston, M. Place Attachment in Deprived Neighbourhoods: The Impacts of Population Turnover and Social Mix. Housing Stud. 2012, 27, 208-231. [CrossRef]

81. Stoiljković, B. Implementation of the Concept of Individualization of Residential Architecture in the Context of Improving the Quality of Multifamily Housing in Serbia. Ph.D. Thesis, Faculty of Civil Engineering and Architecture, University of Niš, Niš, Serbia, 8 October 2015. (In Serbian)

82. Dekker, K.; De Vos, S.; Musterd, S.; Van Kempen, R. Residential satisfaction in housing estates in European cities: A multi-level research approach. Hous. Stud. 2011, 26, 479-499. [CrossRef]

83. Adriaanse, C.C.M. Measuring residential satisfaction: A residential environmental satisfaction scale (RESS). J. Hous. Built Environ. 2007, 22, 287-304. [CrossRef] 